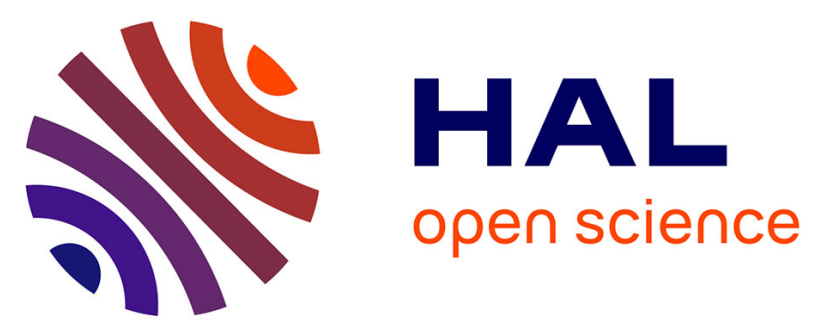

\title{
Synthesis of Pyridoclax Analogues: Insight into Their Druggability by Investigating Their Physicochemical Properties and Interactions with Membranes
}

\author{
Martina de Pascale, Domenico Iacopetta, Marc Since, Sophie Corvaisier, V.
} Vié, G. Paboeuf, Didier Hennequin, Serge Perato, Marcella de Giorgi, Maria Stefania Sinicropi, et al.

\section{To cite this version:}

Martina de Pascale, Domenico Iacopetta, Marc Since, Sophie Corvaisier, V. Vié, et al.. Synthesis of Pyridoclax Analogues: Insight into Their Druggability by Investigating Their Physicochemical Properties and Interactions with Membranes. ChemMedChem, 2020, 15 (1), pp.136-154. 10.1002/cmdc.201900542 . hal-02434628

\section{HAL Id: hal-02434628}

\section{https://hal-univ-rennes1.archives-ouvertes.fr/hal-02434628}

Submitted on 30 Jan 2020

HAL is a multi-disciplinary open access archive for the deposit and dissemination of scientific research documents, whether they are published or not. The documents may come from teaching and research institutions in France or abroad, or from public or private research centers.
L'archive ouverte pluridisciplinaire HAL, est destinée au dépôt et à la diffusion de documents scientifiques de niveau recherche, publiés ou non, émanant des établissements d'enseignement et de recherche français ou étrangers, des laboratoires publics ou privés. 


\section{Synthesis of new Pyridoclax analogs: Insights into their druggability through investigation of their physicochemical properties and their interactions with membranes}

Martina DE PASCALE,,${ }^{\left[a{ }^{*}\right.}$ Domenico IACOPETTA, ${ }^{[b]^{*}}$ Marc SINCE, ${ }^{[a]}$ Sophie CORVAISIER, ${ }^{[a]}$ Véronique VIE, ${ }^{[c]}$ Gilles PABOEUF, ${ }^{[c]}$ Didier HENNEQUIN, ${ }^{[d]}$ Serge PERATO, ${ }^{[a]}$ Marcella DE GIORGI, ${ }^{[a]}$ Maria Stefania SINICROPI, ${ }^{[b]}$ Jana SOPKOVA-DE OLIVEIRA SANTOS, ${ }^{[a]}$ Anne-Sophie VOISIN-CHIRET, ${ }^{\text {[a }{ }^{* *}}$ Aurélie MALZERT-FREON[a] ${ }^{* *}$

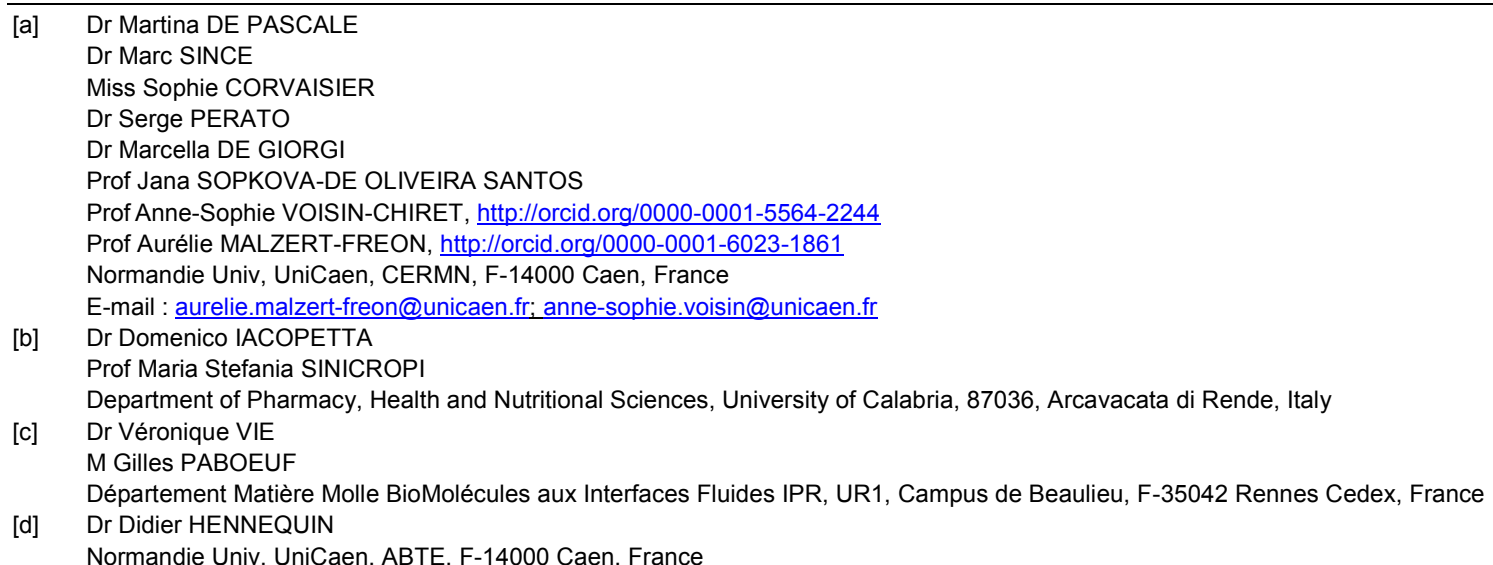

${ }^{\star}$ Equal authorship contribution

${ }^{* *}$ Corresponding Authors

Supporting information for this article is given via a link at the end of the document

\begin{abstract}
Pyridoclax is considered as a promising anticancer drug, acting as a protein-protein interactions disruptor, with potential applications in the treatment of ovarian, lung, and mesothelioma cancers. 18 sensibly selected structural analogs of Pyridoclax were synthesized, and their physico-chemical properties were systematically assessed, and analyzed. Moreover, considering that drug-membrane interactions play an essential role to understand drugs mode of action and eventual toxic effects, membrane models were used to investigate such interactions in the bulk (liposomes) and at the air-water interface. The measured experimental data on all original oligopyridines have permitted to assess relative differences in terms of physico-chemical properties which could be determinant for their druggability, and hence for their drug development.
\end{abstract}

\section{Introduction}

The major role of Mcl-1 in the carcinogenesis of a wide variety of tumor localizations has been established, that has gradually led to the designation of $\mathrm{Mcl}-1$ as a priority therapeutic target. ${ }^{[1]}$ In addition, the major role of the pro-apoptotic proteins $\mathrm{Mcl}-1$ and $\mathrm{Bcl}-\mathrm{X}_{\mathrm{L}}$ overexpression and cooperation in protecting tumor cells against apoptosis and acquiring resistance to many anticancer drugs is now well known. ${ }^{[2,3]}$ In particular, overexpression of Mcl1 was identified as one of the major factors of resistance to inhibitors of Bcl-xL (Navitoclax) or Bcl-2 (Venetoclax). In this context, great efforts have been directed towards the development of therapeutic drugs able to inhibit Mcl-1 in cancer cells to lead to efficient cell death.

Pyridoclax is an oligopyridine, consisting of four pyridine rings substituted by methyl group on the ortho position of the second ring and by a styryl group on the third ring. Using surface plasmon resonance assay, it has been established that this lead compound is able to bind to $\mathrm{Mcl}-1 .{ }^{[4]}$ When used in combination with $\mathrm{Bcl}-\mathrm{X}_{\mathrm{L}}$ targeting siRNA or with ABT-737, Pyridoclax is able to induce apoptosis in ovarian, lung, and mesothelioma cancer cells. Pyridoclax is not cytotoxic when it administered as a single agent. ${ }^{[4]}$ Thus, considering the dramatic situation of patients with such tumors resistant to conventional chemotherapy, this opens interesting perspectives concerning the use of Pyridoclax and its derivatives in combination with $\mathrm{Bcl}-\mathrm{x}_{\mathrm{L}}$ targeting molecules. In vivo preclinical studies are now required to establish the potential interest of such innovative molecule.

Considering that the diverse substitutions realized on members of the oligopyridine family, and in particular on Pyridoclax, have led to compounds that do not scrupulously respect the 5 Lipinski's rules, ${ }^{[5,6]}$ it appears essential to deeply characterize their physicochemical properties before any in vivo evaluation. Indeed, poor solubility and/or poor permeability lead to insufficient absorption and, in fine, to low bioavailability. ${ }^{[7]}$ In these conditions, the therapeutic potential of these molecules could be misevaluated. 
In the present study, we propose to experimentally determine relevant physico-chemical properties of Pyridoclax and some of its reasonably selected structural analogs listed in Figure 1, in order to establish structure-physicochemical properties relationships of these oligopyridines of therapeutic interest.

\section{Results and Discussion}

\section{Library of studied Pyridoclax derivatives}

The synthesis of oligopyridines based on Bohlmann-Rahtz reaction highlights low yields and numerous reaction steps. To overcome these difficulties, we have developed the Garlanding concept which allows building a long linear chain from one ring by the implementation of regioselective iterative cross coupling metallocatalyzed reactions between boronic species and di- or trihalogenated compounds. ${ }^{[8-10]}$

This flexible and highly reproducible methodology permitted to obtain about hundred new bi-, ter-, quater-, quinque- and sexipyridines, phenylpyridines, and thienylpyridines with satisfactory yields. ${ }^{[11-16]}$ Starting from a quaterpyridine, Pyridoclax named MR29072, we have designed and synthesized new oligopyridines in order to investigate the influence of some structural modifications on their physico-chemical properties. Considering that MR29072 has a bipyridine core in the middle of the molecule, substituted by a methyl and a styryl group in the 5 position, 1) the influence of the number of aromatic rings, 2) the nature and position of lateral substituents, 3 ) the nitrogen position on terminal pyridines, 4) replacement of central or terminal pyridines with a phenyl ring, and 5) functionalization by introducing polar groups on one end were investigated in this study (Figure 1).

Synthesis of Pyridoclax derivatives with various pyridyl-chain length

In order to study the influence of the number of aromatic rings, we synthesized Pyridoclax analogs with 2, 3, 5 and 6 aromatic rings as the main chain, and with or without the styryl motif. To access the compounds MR33715 and MR33716, we used the common synthetic intermediate 5-bromo-2-(6-iodo-5-methyl-3-pyridyl)-3$\left[(E)\right.$-styryl]pyridine previously described; ${ }^{[4]}$ taking advantage of the difference in reactivity of the halogens $(I>B r)$, the compound 1, 2-(6-bromo-3-pyridyl)-5-[5-bromo-3-[(E)-styryl]-2-pyridyl]-3methylpyridine, was obtained with a relative selectivity with a yield of $72 \%$ (Scheme 1 ).

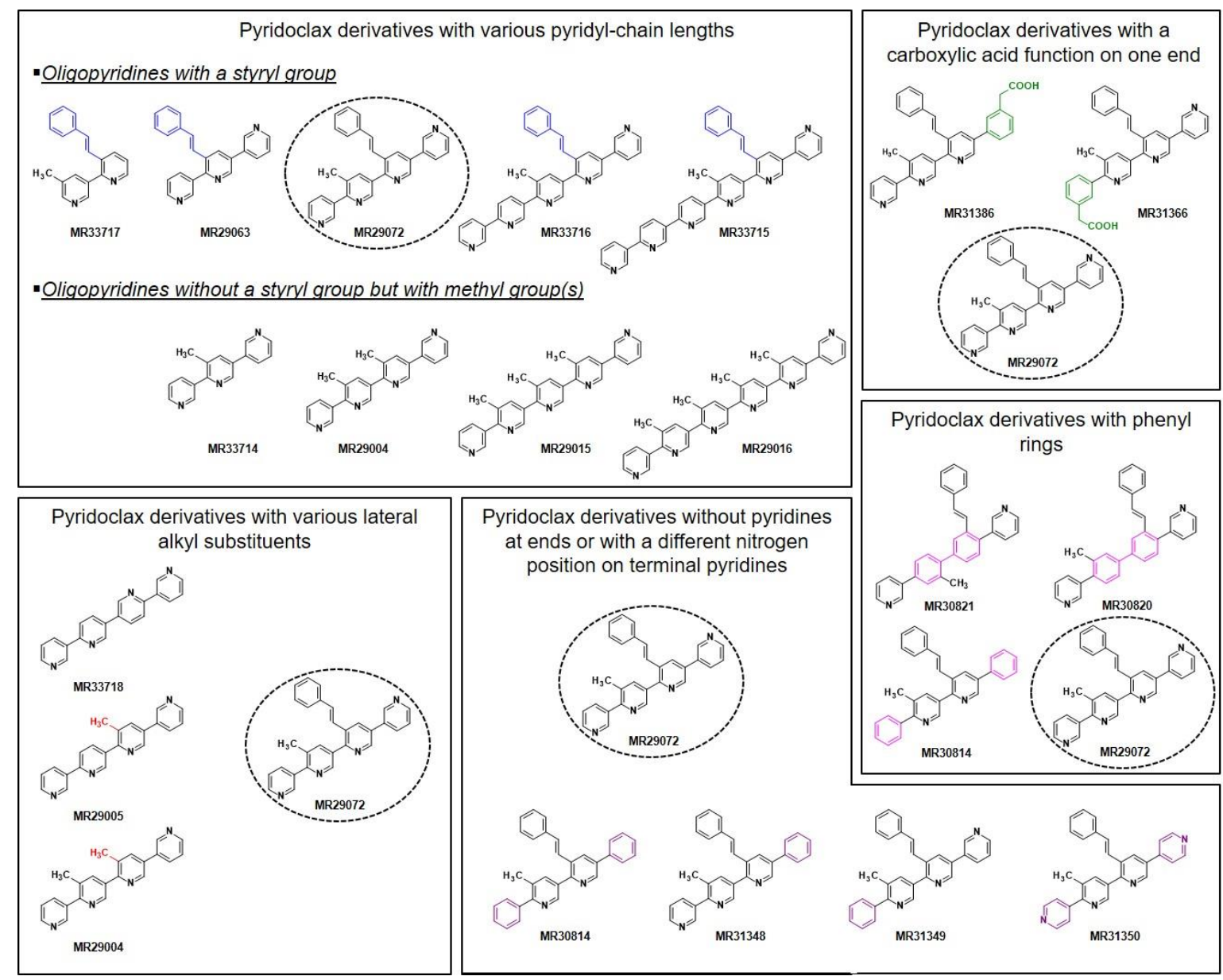

Figure 1. Classification of Pyridoclax derivatives from structural modifications. 


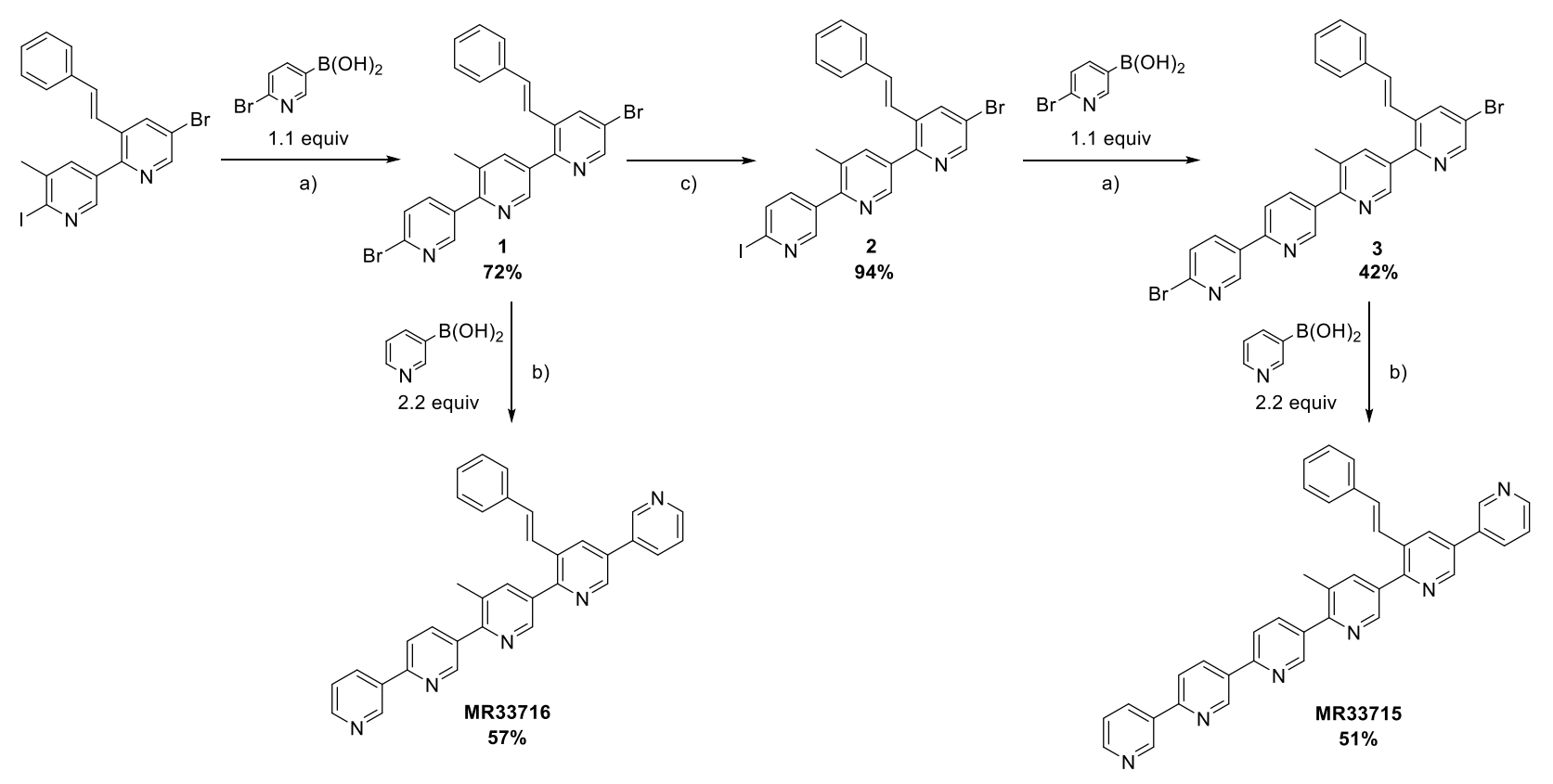

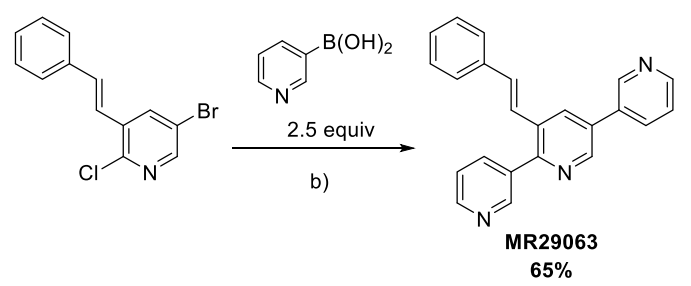<smiles>Cc1cc(Br)cnc1Br</smiles>

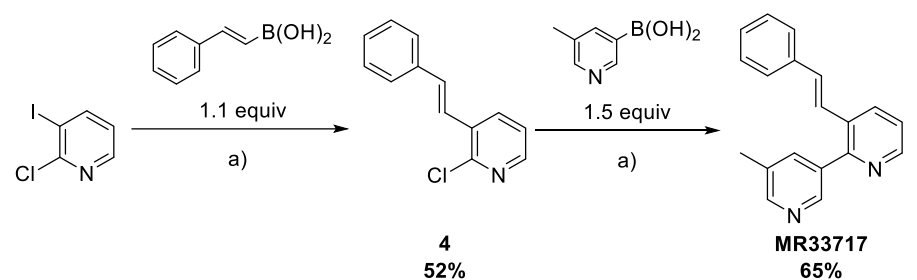

Scheme 1. Chemical procedure to synthesize oligopyridines MR33716, MR33715, MR29063, MR33717 and MR33714. Reagents and conditions: (a) $P d(P P h 3) 4$ or $\mathrm{PdCl}_{2}$ (dppf) (5\% mol), $\mathrm{K}_{3} \mathrm{PO}_{4}$ (2.5 equiv), 1,4-dioxane, reflux, 3-24 h; (b) Pd( $\left.\mathrm{PPh}_{3}\right)_{4}(10 \% \mathrm{~mol})$, base $\left(\mathrm{Na}_{2} \mathrm{CO}_{3}\right.$ or $\left.\mathrm{K}_{3} \mathrm{PO}_{4}\right)(5.0$ equiv), 1,4-dioxane, reflux, 2-3 h; (c) $\mathrm{Nal}$ (10.0 equiv), $\mathrm{CH}_{3} \mathrm{COCl}$ (1.5 equiv), acetonitrile, $100^{\circ} \mathrm{C}, 1 \mathrm{~h}, \mathrm{C}=0.4 \mathrm{M}$, microwaves.

The compound 1 was engaged either in a second Suzuki-Miyaura cross coupling reaction with 2.2 equivalents of 3 -pyridylboronic acid to afford MR33716 (57\% yields) or, in a halogen-halogen exchange to exploit the difference of the reactivity between iodine and bromine. The bromo-iodo-compound $\mathbf{2}$ was then engaged in two successive Suzuki-Miyaura cross coupling reactions with 6bromo-3-pyridylboronic acid and 3-pyridylboronic acid to give MR33715 (51\% yields). MR29063 has been produced $(61 \%$ yields) by the implementation of a double Suzuki-Miyaura cross coupling reaction from $(E)$-5-bromo-2-chloro-3-styrylpyridine,,$^{[4]}$ with 2.5 equivalents of 3 -pyridylboronic acid: in this case, the nature and the position of halogens on the pyridine ring do not allow a regioselective coupling reaction, making it possible to obtain the expected terpyridine.

From 2-chloro-3-iodopyridine, we obtained MR33717 (by the implementation of an iterative Suzuki-Miyaura cross coupling reaction with, firstly $(E)$-styrylboronic acid to obtain intermediately (E)-2-chloro-3-styrylpyridine 4 (52\% yields) and, secondly with 5methylpyridin-3-ylboronic acid to produce MR33717 (65\% yields).
To obtain MR29015 (Scheme 2), 5-bromo-2-iodo-3methylpyridine was engaged in a Suzuki-Miyaura cross coupling reaction with 1.25 equivalents of 6-bromo-5-methyl-3pyridylboronic acid to give 2-bromo-5-(5-bromo-3-methyl-2pyridyl)-3-methylpyridine 5 , which is leading to 5-bromo-2-(6iodo-5-methyl-3-pyridyl)-3-methyl-pyridine 6 via a halogenhalogen exchange. The bromo-iodo-pyridine 6 was then engaged in a second Suzuki-Miyaura cross coupling reaction with 1.25 equivalents of 6-bromo-5-methyl-3-pyridylboronic acid to give 5bromo-2-[6-(6-bromo-5-methyl-3-pyridyl)-5-methyl-3-pyridyl]-3methyl-pyridine 7 . The last step consists in a third Suzuki-Miyaura cross coupling reaction with 2.5 equivalents of 3-pyridylboronic acid to give MR29015 (74\% yields).

MR29004 and MR29016, respectively four and six pyridine ring compounds, were synthesized using Garlanding methodology as it was previously described. ${ }^{[17]}$ 
<smiles>[Y]c1cc(-c2cc(Br)cc(C)c2C)ncc1C(C)C(C)C(C)C</smiles>

a)

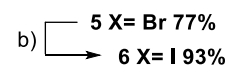<smiles>Cc1cc(-c2cccnc2)cc(-c2cc(C)c(-c3cnc(-c4cccnc4)c(C)c3)cn2)c1</smiles>

Scheme 2. Chemical procedure to synthesize oligopyridine MR29015. Reagents and conditions: (a) $\mathrm{Pd}\left(\mathrm{PPh}_{3}\right)_{4}(5 \% \mathrm{~mol}), \mathrm{Na}_{2} \mathrm{CO}_{3}$ (2.5 equiv), 1,4dioxane, reflux, $20 \mathrm{~h}$; (b) NIS (1.1 equiv), acetonitrile, reflux, $5 \mathrm{~h}$; (c) $\mathrm{Pd}\left(\mathrm{PPh}_{3}\right)_{4}$ (10\% mol), $\mathrm{Na}_{2} \mathrm{CO}_{3}$ (5.0 equiv), 1,4-dioxane, reflux, $20 \mathrm{~h}$.

Synthesis of Pyridoclax derivatives with a carboxylic acid function on one end

The implementation of iterative cross-coupling reactions between boronic species and di- or tri-halogenated compounds whose reactivity is different because of their nature or their position on the pyridine, allowed us to obtain Pyridoclax derivatives as $(E)-2$ (3-(5-methyl-3'-styryl-[3,2':5',3'-terpyridin]-6-yl)phenyl)acetic acid MR31366 and (E)-2-(3-(5'-methyl-3-styryl-[2,3':6',3"-terpyridin]-5yl)phenyl)acetic acid MR31386. ${ }^{[18]}$
Synthesis of Pyridoclax derivatives with substituted phenyl rings To prepare the bisphenylpyridine MR30821, we used the strategy described in Scheme 3. In one hand, we first synthesized phenylpyridine 8 from 3-pyridylboronic acid and 2-bromo-5iodotoluene with a yield of $85 \%$. The use of a non-halogenated boronic acid limits side reactions and confirms the difference in reactivity between the iodine and bromine atoms, despite the presence of a bulky methyl substituent. Phenylpyridine 8 was then engaged in a halogen-metal exchange reaction carried out using $n$-butyllithium in THF at $-78^{\circ} \mathrm{C}$, followed by the addition of triisopropyl borate to easily conduct to the corresponding boronic acid 9 with $68 \%$ yield. In the other hand, from 2,5dibromobenzaldehyde, the aldehyde $\mathbf{1 0}$ is obtained with a good yield of $80 \%$ and selectively without trace of its isomer because of the presence of the aldehyde function which makes possible the orientation of the cross coupling reaction towards the formation of the carbon-carbon bond in ortho position. Then, the aldehyde 10 was engaged with boronic acid 9 in a Suzuki-Miyaura cross coupling reaction leading to the formation of bisphenylpyridine $\mathbf{1 1}$ with excellent yield (93\%). A Horner-Wadsworth-Emmons reaction was carried out in the presence of 1 equivalent of phosphonate and 2 equivalents of potassium hydroxide and leads to styrylphenylpyridine MR30821 with good yields (85\%).

A relatively similar procedure, previously described, ${ }^{[4]}$ was used to access to MR30820.<smiles>CCC(C)=Nc1ccc(I)cc1C</smiles>

a)<smiles>Cc1cc(-c2cccnc2)ccc1Br</smiles>

8<smiles>BrCI</smiles>

b) )<smiles>Cc1cc(Br)ccc1-c1cccnc1</smiles><smiles>Cc1cc(-c2cccnc2)ccc1O</smiles>

9

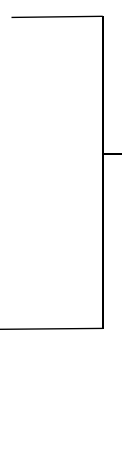

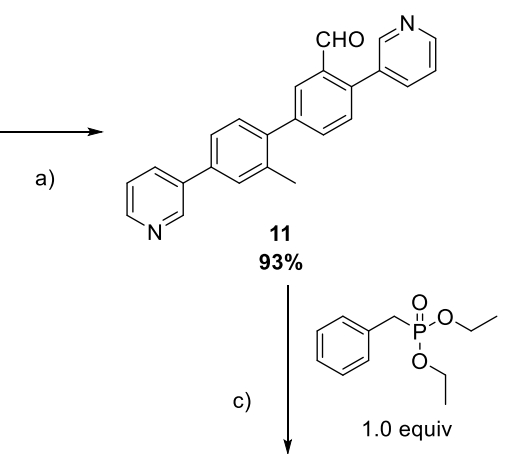<smiles>Cc1cc(-c2cccnc2)ccc1-c1ccc(/C=C/c2ccccc2)c(-c2cccnc2)c1</smiles>

Scheme 3. Chemical procedure to synthesize oligopyridine MR30821. Reagents and conditions: (a) $\left.\mathrm{Pd}_{(\mathrm{PPh}}\right)_{4}(5 \% \mathrm{~mol}), \mathrm{Na}_{2} \mathrm{CO} 3(2.5$ equiv), 1,4 -dioxane, reflux, $20 \mathrm{~h}$; (b) $n$-BuLi (1.3 equiv), triisopropylborate (1.3 equiv), THF dry, $-78^{\circ} \mathrm{C}, 2 \mathrm{~h}$; (c) KOH (2.0 equiv), THF, reflux, $20 \mathrm{~h}$.

Synthesis of Pyridoclax derivatives without pyridines at ends or with a different nitrogen position on terminal pyridines

Concerning the preparation of Pyridoclax analogs MR30814, MR31348, MR31349 and MR31350, either they were synthesized using 2.5 equivalents of corresponding (het)aryl boronic species in order to produce analogs with identical ends (MR30814 and MR31350), either, they were prepared with two different (het)aryl boronic species in order to produce analogs with different ends 
(MR31348 and MR31349). Moreover, the choice of the synthesis pathway was determined in function of the reactivity of different boronic species as it was previously described. ${ }^{[4]}$

Synthesis of Pyridoclax derivatives with various lateral alkyl substituents

MR29005 was synthesized using Garlanding methodology as it was previously described. ${ }^{[17]}$ Concerning the symmetric quaterpyridine MR33718, 2,5-dibromopyridine was engaged in a Suzuki cross coupling reaction with 3-pyridylboronic acid to give 5-bromo-2-(3-pyridyl)pyridine 12 (Scheme 4).

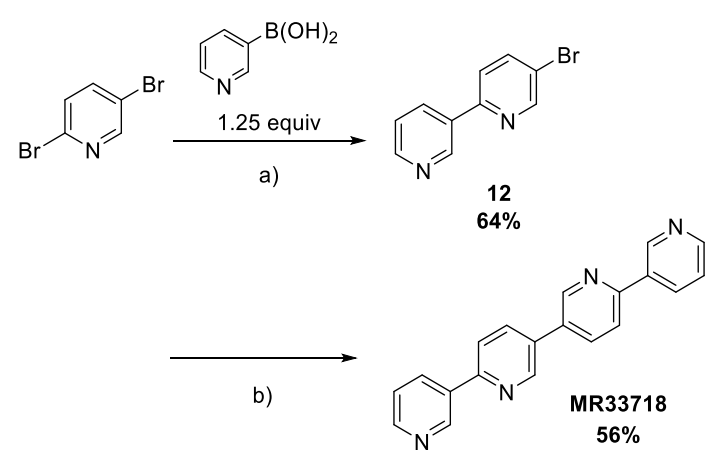

Scheme 4. Chemical procedure to synthesize oligopyridine MR33718. Reagents and conditions: (a) $\mathrm{Pd}\left(\mathrm{PPh}_{3}\right)_{4}$ (5\% mol), $\mathrm{Na}_{2} \mathrm{CO}_{3}$ (2.5 equiv), 1,4dioxane, reflux, $20 \mathrm{~h}$; (b) bispinacolato diboron (0.52 equiv), $\mathrm{PdCl}_{2}$ (dppf) (10\% $\mathrm{mol}$ ), KOAc (2.5 equiv), 1,4-dioxane, reflux, $3 \mathrm{~h}$.
Then, the synthesis of boronic ester of bromobipyridine and its cross coupling reaction with bromobipyridine 12 was realized in an one-pot reaction.The quaterpyridine MR33718 was obtained with good yield (56\%).

All 19 studied compounds were synthesized (procedures are detailed in the Experimental Section) and each structure was characterized by standard methods $\left({ }^{1} \mathrm{H}\right.$ - and $\left.{ }^{13} \mathrm{C}-\mathrm{NMR}\right)$.

\section{Determination of the fundamental physico-chemical properties of Pyridoclax and of its derivatives}

To predict successful drug development from molecular properties, Lipinski proposed "the rules of 5 " (RO5) relating to the importance of molecular weight $(<500 \mathrm{~g} / \mathrm{mol})$, the number of solvent hydrogen-bond donors (HBD) and acceptors (HBA) $(<5$ $\mathrm{HBD},<10 \mathrm{HBA}$ ), the $\log \mathrm{P}$ value (calc $\log \mathrm{P}<5$ ). ${ }^{[5]}$ In addition to these $\mathrm{RO} 5$, other properties have also to be assessed as they are considered to influence oral bioavailability. ${ }^{[19]}$ So, for each compound, calculated logP (i.e., calc logP), acidity (i.e., calc pKa), HBA ability, molecular weight, the number of rotatable bonds, that of aromatic rings into the scaffold, the number of lateral alkyl substituents, and the polar surface area (i.e., PSA) were estimated using computational chemistry programs. Each compound was also evaluated experimentally for lipophilicity (chrom $\log \mathrm{P}$ ), thermodynamic solubility, and effective permeation rate (i.e., Pe) (Table 1).

pKa

As all of the studied compounds present at least two pyridines in their scaffold, the acidic dissociation constants were calculated in order to explore ionization state of the studied compounds.

\begin{tabular}{|c|c|c|c|c|c|c|c|c|c|c|c|}
\hline $\begin{array}{l}\text { Cpd } \\
\text { [MR] }\end{array}$ & $\begin{array}{c}\mathrm{MW} \\
{[\mathrm{g} / \mathrm{mol}]}\end{array}$ & $\begin{array}{l}\text { \# aromatic } \\
\text { rings in } \\
\text { scaffold }\end{array}$ & $\begin{array}{l}\text { \# lateral alkyls } \\
\text { substituents }\end{array}$ & $\# \mathrm{HBA}$ & $\begin{array}{c}\text { \# Rotatable } \\
\text { bond }\end{array}$ & $\begin{array}{l}\text { PSA } \\
{\left[\AA^{2}\right]}\end{array}$ & $\begin{array}{l}\text { Calc } \\
\text { pKa }\end{array}$ & $\begin{array}{l}\text { Calc } \\
\log P\end{array}$ & $\begin{array}{l}\text { Chrom } \\
\log P\end{array}$ & $\begin{array}{l}\text { Aq. Solub. } \\
{[\mu \mathrm{M}]}\end{array}$ & $\begin{array}{c}\mathrm{Pe} \\
{[\mathrm{nm} / \mathrm{s}]}\end{array}$ \\
\hline 29072 & 426.5 & 4 & 1 & 4 & 5 & 45.0 & 4.84 & 5.83 & 4.4 & $9.4 \pm 0.1$ & 160 \\
\hline 33717 & 272.3 & 2 & 1 & 2 & 3 & 22.5 & 4.81 & 4.69 & 3.7 & $138.1 \pm 6.4$ & 891 \\
\hline 29063 & 335.4 & 3 & 0 & 3 & 4 & 33.8 & 4.80 & 4.59 & 3.7 & $18.9 \pm 0.4$ & 1,200 \\
\hline 33716 & 503.6 & 5 & 1 & 5 & 6 & 56.3 & 4.85 & 6.6 & 4.6 & $5.8 \pm 2.1$ & 21 \\
\hline 33715 & 580.7 & 6 & 1 & 6 & 7 & 67.6 & 4.86 & 7.37 & 5.3 & n.d. & n.d. \\
\hline 33714 & 247.1 & 3 & 1 & 3 & 2 & 33.8 & 4.85 & 2.35 & 1.7 & $384 \pm 43$ & 1,130 \\
\hline 29004 & 338.1 & 4 & 2 & 4 & 3 & 45.0 & 4.89 & 3.58 & 2.5 & $26.8 \pm 3.5$ & 260 \\
\hline 29015 & 429.2 & 5 & 3 & 5 & 4 & 56.3 & 4.91 & 4.82 & 3.1 & n.d. & 0 \\
\hline 29016 & 520.0 & 6 & 4 & 6 & 5 & 67.6 & 4.94 & 6.06 & 3.7 & n.d. & n.d. \\
\hline 33718 & 310.1 & 4 & 0 & 4 & 3 & 45.0 & 4.66 & 2.65 & 2.6 & n.d. & 719 \\
\hline 29005 & 324.1 & 4 & 1 & 4 & 3 & 45.0 & 4.87 & 3.12 & 2.5 & $70.9 \pm 3.1$ & 1,200 \\
\hline 30814 & 424.5 & 4 & 1 & 2 & 5 & 22.5 & 4.17 & 8.45 & 6.8 & $0.7 \pm 0.8$ & 0 \\
\hline 31348 & 425.5 & 4 & 1 & 3 & 5 & 33.8 & 4.43 & 7.14 & 5.9 & $2.5 \pm 2.9$ & 150 \\
\hline 31349 & 425.5 & 4 & 1 & 3 & 5 & 33.8 & 4.75 & 7.14 & 5.7 & $1.2 \pm 0.6$ & 160 \\
\hline 31350 & 426.5 & 4 & 1 & 4 & 5 & 45.0 & 4.92 & 5.83 & 4.4 & $20.5 \pm 0.7$ & 160 \\
\hline 30820 & 424.5 & 4 & 1 & 2 & 5 & 22.5 & 5.01 & 7.66 & 6.4 & $1.1 \pm 0.4$ & 2 \\
\hline 30821 & 424.5 & 4 & 1 & 2 & 5 & 22.5 & 5.01 & 7.66 & 6.3 & $<1$ & 0 \\
\hline 31386 & 483.5 & 4 & 1 & 5 & 7 & 71.9 & 4.21 & 6.77 & ND & $>250$ & 470 \\
\hline 31366 & 483.5 & 4 & 1 & 5 & 7 & 71.9 & 4.47 & 6.77 & ND & $>250$ & 270 \\
\hline
\end{tabular}


pKa values were estimated at physiological $\mathrm{pH}$ of 7.4 , using ChemAxon software (Marvin 16.1.4.0, 2016, ChemAxon (http://www.chemaxon.com/)), with a method based on the partial charge calculation of atoms in the molecule. Only the most basic pKa was retained (Table 1). Calc pKa values appear as very narrowly distributed, and remain lower than 5.1. Except MR31366 and MR31386, that have a meta-phenylacetic acid group at one of terminal pyridines (acidic pKa of 5.01, and 4.78, respectively), all synthesized compounds present a predominant unionized form at $\mathrm{pH}$ 7.4. It should be pointed out that molecules with pKa values lower than 8 , as in the present case, are expected to avoid interactions with P-glycoprotein (Pgp), ${ }^{[20,21]}$ and thus, should bypass unfavorable mechanisms as multi-drug resistance.

\section{Lipophilicity}

Lipophilicity is a major physico-chemical parameter to consider in drug design because of its omnipotent impact on druggability parameters (i.e. solubility and permeation), ${ }^{[22,23]}$ as well as on in vivo pharmacokinetic parameters (i.e. absorption, plasma protein binding, phase I metabolization, and hERG binding). ${ }^{[5,24]}$ Logarithms of partition coefficients ( $\log \mathrm{P})$ were first calculated using several software programs, i.e., Discovery Studio, Schrödinger, ChemAxon, and Molinspiration. In parallel, except for ionized MR31366 and MR31386 at pH=11.5, the $\log P$ (chrom $\log \mathrm{P}$ ) were also measured using an isocratic liquid chromatography method, in non-ionized conditions. ${ }^{[25,26]}$ The best correlation $(R=0.9101)$ between calc $\log P$ and chrom log $P$ values was found using the ChemAxon method based on the atomic log $\mathrm{P}$ increments. ${ }^{[27]}$ Considering that the calculated values were systematically higher than those measured, the softwares should present some limitations to efficiently predict partition coefficient values in these oligopyridines. Such results highlight the need of an experimental determination as suggested in other studies. ${ }^{[28]}$ In regard of the chrom logP values varying from 1.7 to 6.8 (Table 1 ), the studied compounds can be considered as moderately to highly lipophilic.

MR29072, MR30814, MR31348, MR31349, MR31350, MR30820, and MR30821 are close molecular weights compounds constituted by 4 aromatic rings in garland, and with a methyl and a styryl group on the central rings. In this series, substitution of a pyridine by a phenyl ring leads to an obvious and expected increase in chrom logP values, as observed by comparing MR29072, MR31350 (4 Pyr, chrom logP = 4.4) to MR31348, MR31349 (1 Phe, 3 Pyr, chrom logP = 5.9 and 5.7, respectively), and to MR30821, MR20820, MR30814 (2 Phe, 2 Pyr, chrom logP $=6.3$ to 6.8 ). If the phenyl groups are positioned in the middle or at the ends of the molecule, chrom logP range in the same order of values (MR30814, MR30821, MR30820). Thus, the presence of a nitrogen atom directly influences the lipophilicity of the studied compounds: it may explain the relative polarity and the weak contribution in global molecular lipophilicity.

The influence of the nature of the lateral alkyl substituents on the lipophilicity of oligopyridines was also studied. By considering the quaterpyridines MR33718, MR29005, and MR29004, it appears that the substitution by methyl groups on the two central rings doesn't significantly impact chrom logP.

On the contrary, replacement of a methyl substituent by a styryl group leads to higher molecular weight compounds, with significantly higher chrom logP values. Indeed, for MR33714, MR29004, MR29015, MR29016, a series of oligopyridines with an increasing number of 3-methylpyridinyl groups, chrom $\log P$ values range from 1.7 to 3.7 . For the series characterized by the presence of a lateral hydrophobic styryl group (MR33717, MR29063, MR29072, MR33716, and MR33715), chrom logP values are comprised between 3.7 to 5.3. In both series, addition of pyridine into the garland framework leads to a proportional increase of the chrom $\log \mathrm{P}$ value of about 0.6 per added unit (regression coefficient $\mathrm{R}^{2}>0.94$ ).

\section{Solubility}

Thermodynamic solubility was measured using a miniaturized shake-flask method for all compounds at the exception of MR33718, MR33715, MR29015, and MR29016 whose solubility in DMSO or in water/acetonitrile mixtures was too low to produce standard solutions. In particular, for MR33715, and MR29016, insolubility can be related to the high number of aromatic rings in the garland scaffold $(>5)$, and the resulting high molecular weight $(>500 \mathrm{~g} / \mathrm{mol})$. Indeed, the molecular weight of compounds appears as negatively impact their solubility. On the contrary, solubility seems being positively influenced by PSA and the number of rotatable bonds. Although a moderate chrom $\log P$ value (2.6) and a low molecular weight (310.1 g/mol), MR33718 appears totally insoluble in water and in DMSO. Such a result could be related to the fact that MR33718 is a planar and a symmetric compound, which can hamper its solubilization. ${ }^{[29]}$ The fact that this compound has a negligible dipole moment value (0.001 Debyes as determined using Discovery Studio software) and a high melting temperature $\left(198^{\circ} \mathrm{C}\right)$ corroborates this idea.

The solubility of MR31366 and MR31386, ionized compounds, was found higher than $250 \mu \mathrm{M}$, i.e. the concentration used to prepare supersaturated solutions in our experimental conditions (see Experimental Section).

Other studied molecules show a low aqueous solubility, ranging from 0.7 to $384 \mu \mathrm{M}$. Such a result is reliable to the absence of solvent hydrogen-bond donors (HBD), their lipophilicity, and hence, of the number of the garland units and of the nature of the lateral substituents as previously discussed. Moreover, by comparing MR29072 and MR31350, it appears that the position of the nitrogen groups on terminal pyridines could slightly influence their solubility.

Aqueous solubility is essential for drug candidates. ${ }^{[30]}$ As poor aqueous solubility is likely to result in poor absorption, various solubilization approaches should be further studied, as chemical strategies based on salt formation and prodrug synthesis, or advanced formulation strategies. ${ }^{[31]}$

\section{Permeation ability}

Using a parallel artificial membrane permeability assay (PAMPA), a high throughout technique commonly used in drug discovery to predict passive permeation through biological membranes, ${ }^{[32]}$ the ability of the synthesized garland compounds to cross the gastrointestinal tract (GIT) was evaluated. Because of their complete insolubility in water, even in presence of DMSO, PAMPA studies could not be performed on MR33715 and on MR29016, two compounds with 6 aromatic rings.

A threshold value of $\mathrm{Pe}>100 \mathrm{~nm} / \mathrm{s}$ is the generally accepted threshold value to consider that permeation is not a limiting factor for oral bioavailability. ${ }^{[19]}$ At the exception of MR33716, MR29015, MR30814, MR30820, MR30821, all synthesized molecules present acceptable Pe values (Table 1).

According to the Lipinski's rules, ${ }^{[5]}$ to favor permeation of compounds, the sum of $\mathrm{H}$-bond donors and acceptors via - $\mathrm{NH}$, - 
$\mathrm{OH},-\mathrm{N}$ and $-\mathrm{O}$ atoms must be lower than 5 and 10 , respectively. Furthermore, Veber et al. demonstrated dependencies of $\mathrm{Pe}$ on the polar surface area (PSA) and on the flexibility of the molecule quantified from the number of rotatable bonds (RB). ${ }^{[19]}$ They established selective criteria as follows: PSA $\leq 140 \AA^{2}$, and RB $\leq$ 10. In our molecule pipeline, despite a wide range of $\mathrm{Pe}(0$ to $1,200 \mathrm{~nm} / \mathrm{s}$ ), no compound possesses HBD while HBA, RB, and PSA values remain below fixed limits.

Hydrophobicity is often considered as a key physicochemical property that contributes to the passive membrane permeation of a compound by governing the membrane partition process. ${ }^{[22]}$ Often, for moderately lipophilic compounds, a positive relationship exists between $\mathrm{Pe}$ and calc $\log \mathrm{P}$ while for high lipophilic derivatives (calc $\log \mathrm{P}>3.5$ ), the higher the $\log \mathrm{P}$, the worst the permeation rate is. ${ }^{[33]}$ In our case, no permeable MR30814, MR30820, and MR30821 have high chrom $\log P(\geq 6.3)$. Presence of 2 phenyl groups in these molecules renders them very poorly soluble and no permeable. So, such compounds should be discarded since they will not permit acceptable oral bioavailability. Moreover, considering the absorbance spectra obtained during PAMPA experiments (absorbance levels are lower at the end than at the beginning, results not shown), these compounds may be retained within the membrane because of their high lipophilicity. Permeation within the membrane imposes a decrease in entropy on the molecule whose the free energy cost depends on the size of the permeant. ${ }^{[34]} \mathrm{Pe}$ is negatively correlated to the molecular weight. Considering the no permeable MR33716 and MR29015, formed of 5 aromatic rings, it appears that the number of garland units should be fixed to 4 to permit passive diffusion through membranes, whatever the nature of the lateral alkyl substituents. In these conditions, the molecular weight of compounds remains lower than $500 \mathrm{~g} / \mathrm{mol}$ as fixed in RO5. ${ }^{[5]}$

In regard of these different results, the lead of this family, MR29072 presents acceptable druggability parameters, reliable to a maximum of 4 aromatic rings, and a styryl group on a pyridine. The presence of a carboxylic function at one end (whatever its position) can highly help to enhance molecules hydrophilicity, and solubility in water.

However, such foldamers with more balanced physicochemical properties must also have the potential to be suitable chemical biology tools.

\section{Determination of drug-membrane interactions}

In a medicinal chemical perspective, it may be important to evaluate drug-membrane interactions. Indeed, the chemical compounds penetration and/or their location within biological membranes may result in alterations of membrane permeability, or changes in the performance of the cell. ${ }^{[35]}$ In parallel, drugmembrane interactions can contribute to explain the molecularlevel mechanisms of action of the drugs and even sometimes the side-effects. Considering that studies performed on anticancer drugs have established a correlation between their cytotoxic activity, their location within membrane ${ }^{[36]}$ and their effect on membrane stability or fluidity, ${ }^{[37]}$ interactions between the oligopyridines and biomimetic membranes have been investigated.

Study of the interactions of the oligopyridines with liposomes as membrane models

Liposomes were used as membrane models since they show many physical features very close to natural membranes. ${ }^{[38]}$ Large
Unilamellar Vesicles (LUVs) based on soybean phosphatidylcholine (PC), a mixture of phospholipids with different fatty acids (linoleic acid in majority) mimicking the natural membranes, ${ }^{[39]}$ are widely used as a classical lipid bilayer membrane model. ${ }^{[40]}$ 1,2-dioleoyl-sn-glycero-3-phospho-rac-1glycerol (DOPG) was added in a w/w ratio of $4: 1$ to give $20 \%$ negatively charged head groups, within typical physiological range. ${ }^{[41]}$ Since cholesterol is a constituent present in most mammalian cell membranes, and it is known for its effects on membrane stability and fluidity, liposomes were also formulated with defined proportions of cholesterol. The oligopyridines were incubated in presence of LUVs (see supporting information for their granulometric properties, Table S1), and their emission fluorescence spectra were recorded (see Figure 2 for MR29072, and the supporting information part for other compounds, Figure S1).
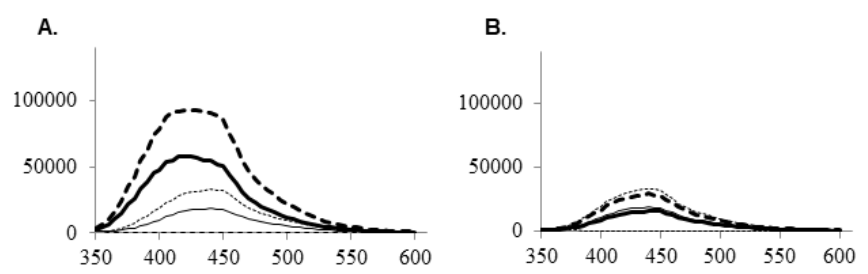

Figure 2. Emission fluorescence spectra of MR29072 with $\lambda_{\text {exc }}=285 \mathrm{~nm}$, recorded at 2 concentrations, in absence or in presence of biomimetic membranes (LUVs formulated A. without (PC:DOPG LUVs) or B. with cholesterol PC:DOPG:chol LUVs): a. - MR29072 at $10 \mu \mathrm{M}$; b.- - - MR29072 at $25 \mu \mathrm{M}$; c. MR29072 at $10 \mu \mathrm{M}+$ LUVs; d. - MR29072 at $25 \mu \mathrm{M}+$ LUVs; e. - LUVs.

In absence of LUVs, MR29072 spontaneously fluoresces, all the more than its concentration is high (Figure 2). This is also the case for the other molecules substituted by a styryl group in the ortho position of the central junction. Such a fluorescence capacity can be valorized, in particular to experimentally assess its partition coefficient, by requiring only few drug amounts, by raw fluorescence spectrophotometry in a microplate assay. ${ }^{[40]}$

In presence of PC:DOPG LUVs, a blueshift and an increase of fluorescence intensity are observed, reflecting the transition of MR29072 from a polar (water) to a less polar environment (membrane), and the immobilization of the compound within the membrane (Figure 2). Such changes in fluorescence spectra are also present for all compounds substituted by a styryl group, except for MR31350 for which only the increase of fluorescence is detected. They are less objectified with LUVs formulated with cholesterol.

For compounds having more than 4 units in their scaffold (MR33716) or being substituted at the end by a polar group (MR31366, MR31386), neither shift nor fluorescence increase are observed. The presence of the LUVs did not affect the fluorescence of compounds without styryl. If incubation of oligopyridines is made with PC:DOPG:chol LUVs, fluorescence intensity does not vary anymore, except for MR30821.

Obtained experimental results suggest possible interactions between some of the studied oligopyridines and LUVs.

To further examine these effects on membrane permeability, LUVs containing a self-quenching concentration of carboxyfluorescein (CF), and formulated without or with cholesterol, were exposed to each oligopyridine (10 or $25 \mu \mathrm{M}$ ). 
Any change in membrane permeability causes the self-quenched CF to leak out the LUVs into the external medium where the probe becomes highly fluorescent. ${ }^{[42]}$

$100 \%$ CF efflux quasi-systematically occurs from PC:DOPG LUVs for the compounds with a styryl group, used at $25 \mu \mathrm{M}$ (Table 2). Except MR33715 whose effects could not be assessed because of its lack of solubility, only the low permeable MR33716 does not lead to CF efflux. For MR31350, for which effect is not obvious on PC:DOPG LUVs, since the blue shift is not observed, only $55 \%$ CF release was quantified. In all cases, the granulometric properties of the LUVs (monodisperse mean diameter of about $100 \mathrm{~nm}$ ) remained unchanged, as determined by Diffusion Light Scattering (DLS) measurements at the end of the experiments (results not shown), even if permeabilization effects are observed.

Table 2. Study of interactions between compounds (10 or $25 \mu \mathrm{M}$ ) and biomimetic membranes quantified from percentage of carboxyfluorescein (CF) release $\left(\lambda_{\mathrm{ex}}=485 / 20 \mathrm{~nm} / \lambda_{\mathrm{em}}=528 / 20 \mathrm{~nm}\right)$ from large unilamellar liposomes (LUVs), formulated with a mixture of phosphatidylcholine (PC) and 1,2-dioleoylsn-glycero-3-phospho-rac-1-glycerol (DOPG) without or with cholesterol (chol), after $4 \mathrm{~h}$ of incubation with studied oligopyridines at room temperature.

$\%$ CF release from PC:DOPG LUVs $\%$ CF release from PC:DOPG:chol LUVs

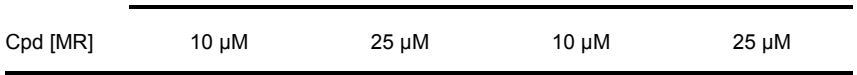

Influence of the number of aromatic rings in oligopyridines with a styryl group

$\begin{array}{ccccc}33717 & 78 & 100 & 20 & 67 \\ 29063 & 45 & 100 & 4 & 30 \\ 29072 & 100 & 100 & 35 & 61 \\ 33716 & 2 & 8 & 0 & 0 \\ 33715 & \text { n.d. } & \text { n.d. } & \text { n.d. } & \text { n.d. }\end{array}$

Influence of the number of aromatic rings in oligopyridines without a styryl group but with methyl group(s)

\begin{tabular}{lcccc}
33714 & 0 & 0 & 0 & 0 \\
29004 & 5 & 8 & 0 & 2 \\
29015 & 0 & 6 & 0 & 2 \\
29016 & 5 & 22 & 0 & 10 \\
Influence of the nature of the lateral alkyl substituents & & \\
33718 & 0 & 3 & 0 & 0 \\
29005 & 1 & 7 & 0 & 3 \\
29004 & 5 & 8 & 0 & 2 \\
29072 & 100 & 100 & 35 & 61 \\
Influence of the presence of pyridines at ends / of nitrogen position on terminal pyridines \\
30814 & 26 & 100 & 7 & 33 \\
31348 & 84 & 100 & 8 & 78 \\
31349 & 92 & 100 & 15 & 64 \\
29072 & 100 & 100 & 35 & 61 \\
31350 & 15 & 55 & 1 & 15 \\
Influence of the substitution of pyridines by phenyl rings & & \\
29072 & 100 & 100 & 35 & 61 \\
30814 & 26 & 100 & 7 & 33 \\
30820 & 100 & 100 & 37 & 100 \\
30821 & 72 & 100 & 30 & 100 \\
Influence of the presence of a carboxylic acid function at one end & 35 & 31 \\
29072 & 100 & 100 & 0 & 0 \\
31386 & 3 & 4 & 0 & 3 \\
31366 & 1 & 1 & & \\
\hline
\end{tabular}

The presence of the bulky hydrophobic group (styryl) facilitates binding to liposomes through hydrophobic interactions, as reported for other amphipathic $\alpha$-helices. ${ }^{[43,44]}$

No CF release was observed for MR31386 and MR31366. In this case, thanks to the presence of the carboxylic acid moiety, ionized molecules might establish repulsive electrostatic interactions with the anionic head groups of DOPG moieties of the membranes. Thus, in spite of the styryl, interactions between these oligopyridines and negatively charged lipid bilayers cannot occur.
Moreover, the hydrophilicity of both molecules probably leads to lowering of the hydrophobic driving force for the binding. ${ }^{[45]}$

The presence of cholesterol in the phospholipid membrane bilayer largely influences the levels of quenching of CF by oligopyridines. Even at the highest tested concentration, only two molecules are able to induce CF efflux: MR30820 and MR30821 two highly hydrophobic compounds.

Cholesterol greatly influences the depth of molecules in membranes ${ }^{[46]}$. Since after intercalation between the fatty acid chains of phospholipids, ${ }^{[47]}$ cholesterol presents a membrane condensing effect ${ }^{[48]}$, it is coherent that interactions between oligomers and bilayers decrease in case of PC:DOPG:chol LUVs. Potential interactions between oligomers and biomimetic membranes may be of interest for anticancer molecules. For example, for compounds like tamoxifen, a drug widely used in the treatment breast cancer and also brain, liver and pancreas tumors, it was shown that the perturbation of the lipid bilayer structure by this amphiphilic molecule of highly lipophilic character may contribute to its multiple mechanisms of anticancer action. ${ }^{[37]}$ Therefore, such effects should be taken into consideration to interpret results of the pre-clinical assays performed on the studied oligopyridines, and in particular those with a styryle, in the future.

The membrane location of oligopyridines was further studied by fluorescence quenching measurements using DPH and TMA$\mathrm{DPH}$ as fluorescence probes. The precise positions of these fluorophores along the membrane depth plane are well established: DPH probe is supposed to have a deep location and a parallel alignment to the acyl chains while TMA-DPH probe, due to its amphipathic character, is anchored to the surface of the membrane, within the phospholipids polar head groups. ${ }^{[37,49]}$ The extent of fluorescence quenching of a membrane bound fluorophore provides a measure of the accessibility of the quencher (here, the studied oligopyridine) to the fluorophore. Consequently, it is also possible to estimate the quencher molecule's location within the lipid bilayer. ${ }^{[50]}$ Fluorescence quenching can be described by the Stern-Volmer equation ${ }^{[51]}$ :

$\mathrm{I}_{0} / \mathrm{l}=1+\mathrm{K}_{\mathrm{sv}}[\mathrm{Q}]$

where $I_{0}$ and $I$ are the corrected fluorescence intensity of the fluorophores (DPH or TMA-DPH) in the absence and presence of the drug, respectively; [Q] is the concentration of the quencher (oligopyridine); $\mathrm{K}_{\mathrm{SV}}$ is the Stern-Volmer constant.

The sensitivity of DPH or TMA-DPH to the fluorescence quenching by the oligopyridines is rather weak in comparison with our reference, rifampicin. ${ }^{[52]}$ From results (Table 3 ), only compounds having 4 rings, either phenyls and/or pyridines, with a styryl group attached on a central pyridine are able to quench the probes when they are used at the concentration of $25 \mu \mathrm{M}$. In particular, MR31348 and MR31349, which were found permeable but highly hydrophobic (chrom logP > 5) would be more particularly able to accumulate in the acyl chain regions.

In some cases, the interactions between molecules and membranes, manifested as changes in the physical and thermodynamic properties of the bilayers, are accompanied by undesirable side effects. ${ }^{[53]}$ Thus, drug-membrane interaction studies may constitute a preliminary step to the biological evaluation of their toxicity. ${ }^{[52]}$ 
Table 3. Study of membrane location of oligogypridines from quantification of fluorescence quenching ( $\mathrm{I}_{0} / \mathrm{l}$ as described by the Stern-Volmer equation) of the probes DPH and TMA-DPH in LUVs, formulated with a mixture of phosphatidylcholine (PC) and 1,2-dioleoyl-sn-glycero-3-phospho-rac-1-glycerol (DOPG) without or with cholesterol (chol), after $4 \mathrm{~h}$ of incubation with studied compounds at room temperature.

$I_{0} / \mathrm{l}$ of DPH $\quad I_{0} / \mathrm{l}$ of DPH in $\quad \mathrm{I}_{0} / \mathrm{l}$ of TMA-DPH $\mathrm{I}_{0} / \mathrm{l}$ of TMA-DPH in PC:DOPG PC:DOPG:chol in PC:DOPG in PC:DOPG:chol
LUVs
LUVs
LUVs LUVs

Cpd [MR] $\quad 10 \mu \mathrm{M} \quad 25 \mu \mathrm{M} \quad 10 \mu \mathrm{M} \quad 25 \mu \mathrm{M} \quad 10 \mu \mathrm{M} \quad 25 \mu \mathrm{M} \quad 10 \mu \mathrm{M} \quad 25 \mu \mathrm{M}$

\begin{tabular}{lllllllll}
\hline Influence of the number of aromatic rings & in oligopyridines with a styryl group \\
33717 & 1.1 & 1.1 & 0.9 & 0.8 & 1.1 & 1.2 & 1.0 & 1.1 \\
29063 & 1.0 & 1.1 & 1.0 & 1.1 & 1.0 & 1.1 & 1.0 & 1.0 \\
29072 & 1.3 & 1.2 & 1.3 & 1.4 & 1.2 & 1.2 & 1.1 & 1.0 \\
33716 & 1.0 & 0.8 & 1.1 & 1.2 & 1.3 & 1.4 & 1.4 & 1.1 \\
33715 & n.d. & n.d. & n.d. & n.d. & n.d. & n.d. & n.d. & n.d.
\end{tabular}

Influence of the number of aromatic rings in oligopyridines without a styryl group but with methyl group(s)

\begin{tabular}{|c|c|c|c|c|c|c|c|c|}
\hline 33714 & 1.0 & 0.9 & 0.9 & 1.1 & 1.0 & 1.0 & 1.0 & 1.0 \\
\hline 29004 & 1.0 & 1.0 & 1.0 & 1.0 & 1.0 & 1.1 & 1.0 & 1.0 \\
\hline 29015 & 1.2 & 1.1 & 1.0 & 1.0 & 1.1 & 1.0 & 1.0 & 1.0 \\
\hline 29016 & 1.0 & 1.1 & 1.0 & 1.1 & 1.1 & 1.0 & 1.0 & 1.0 \\
\hline \multicolumn{9}{|c|}{ Influence of the nature of the lateral alkyl substituents } \\
\hline 33718 & 1.0 & 0.9 & 0.8 & 1.0 & 1.0 & 1.0 & 1.0 & 1.1 \\
\hline 29005 & 1.0 & 1.0 & 0.9 & 1.0 & 1.0 & 1.1 & 1.0 & 1.0 \\
\hline 29004 & 1.0 & 1.0 & 1.0 & 1.0 & 1.0 & 1.1 & 1.0 & 1.0 \\
\hline 29072 & 1.3 & 1.2 & 1.3 & 1.4 & 1.2 & 1.2 & 1.1 & 1.0 \\
\hline \multicolumn{9}{|c|}{ Influence of the presence of pyridines at ends / of nitrogen position on terminal pyridines } \\
\hline 30814 & 1.1 & 1.2 & 1.1 & 1.2 & 1.1 & 1.5 & 1.2 & 1.3 \\
\hline 31348 & 1.2 & 1.6 & 1.3 & 1.5 & 1.2 & 2.0 & 1.2 & 1.5 \\
\hline 31349 & 1.1 & 1.4 & 1.2 & 1.6 & 1.1 & 1.5 & 1.2 & 1.3 \\
\hline 29072 & 1.3 & 1.2 & 1.3 & 1.4 & 1.2 & 1.2 & 1.1 & 1.0 \\
\hline 31350 & 1.4 & 1.4 & 1.2 & 1.3 & 1.1 & 1.2 & 1.0 & 0.9 \\
\hline \multicolumn{9}{|c|}{ Influence of the substitution of pyridines by phenyl rings } \\
\hline 29072 & 1.3 & 1.2 & 1.3 & 1.4 & 1.2 & 1.2 & 1.1 & 1.0 \\
\hline 30814 & 1.1 & 1.2 & 1.1 & 1.2 & 1.1 & 1.5 & 1.2 & 1.3 \\
\hline 30820 & 1.0 & 1.0 & 1.1 & 1.1 & 1.0 & 1.0 & 1.0 & 0.8 \\
\hline 30821 & 1.0 & 0.9 & 1.0 & 1.0 & 1.0 & 1.0 & 1.0 & 0.8 \\
\hline \multicolumn{9}{|c|}{ Influence of the presence of a carboxylic acid function at one end } \\
\hline 29072 & 1.3 & 1.2 & 1.3 & 1.4 & 1.2 & 1.2 & 1.1 & 1.0 \\
\hline 1386 & 1.1 & 1.2 & 1.1 & 1.3 & 1.0 & 1.3 & 1.1 & 1.1 \\
\hline 1366 & 1.1 & 1.2 & 1.2 & 1.3 & 1.3 & 1.7 & 1.1 & 1.0 \\
\hline
\end{tabular}

The present oligopyridines have been conceived as $\mathrm{Mcl}-1$ inhibitors. ${ }^{[4]} \mathrm{Mcl}-1$ blocks the progression of apoptosis by binding and sequestering the pro-apoptotic proteins Bak and Bax. These

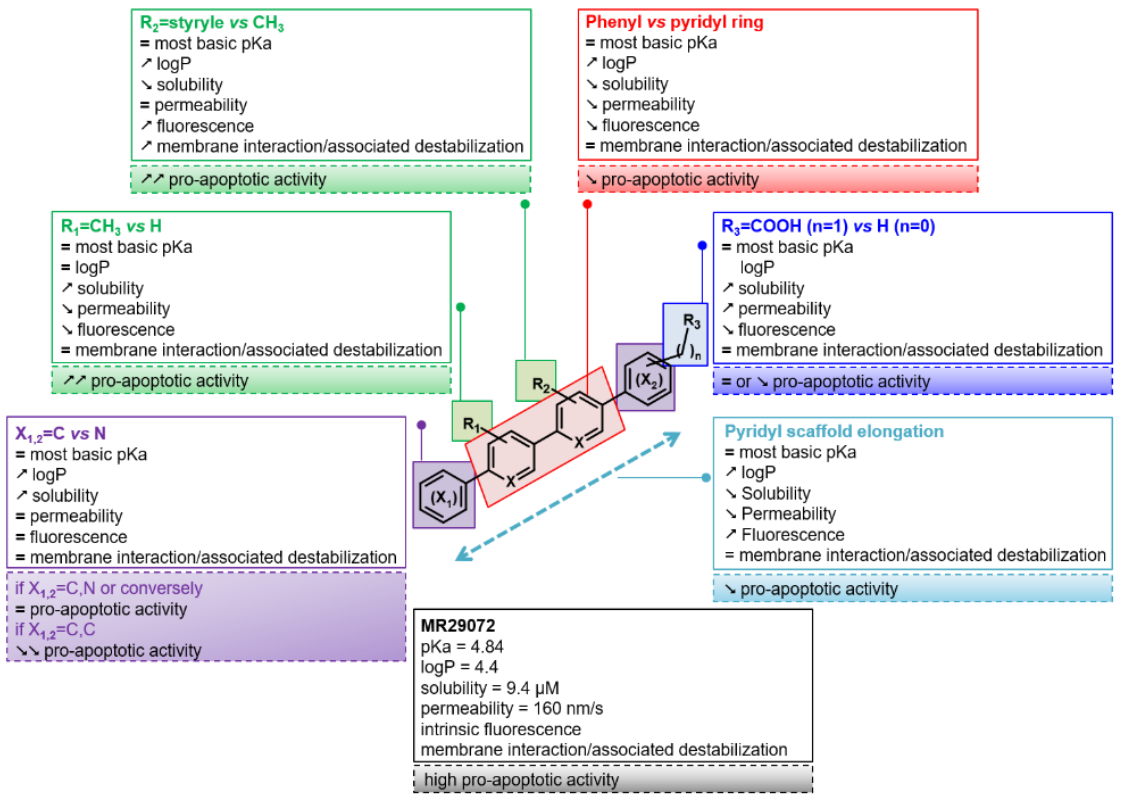

proteins are capable of oligomerize as a result of apoptotic stimuli to form pores in the mitochondrial outer membrane, thus allowing the release of cytochrome $\mathrm{c}$ into the cytoplasm. In turn, cytochrome $c$ induces the activation of caspases leading to apoptosis. ${ }^{[54]}$ Taking into account that pro-apoptotic members of the $\mathrm{Bcl}-2$ protein family induce increase of outer membrane permeability, while anti-apoptotic members prevent this, it seems important to consider with attention the ability of the oligopyridines to interact with membranes.

Figure 3 summarizes the highlighted interactions between the structural modifications performed on Pyridoclax derivatives and their resulting physico-chemical properties. This summary was reinforced by a multivariate statistical treatment by Principal Component Analysis, and a PLS regression analysis performed on parameters that could be encrypted (see supporting information, Figures S2-S5).

The concomitant presence of a styryl group on a pyridine with 4 aromatic rings appears as a maximum to confer good druggability parameters to the studied oligopyridines. This is exactly the case of the lead of this family, MR29072. Interactions between the styryle and biological membranes could occur, which is important to take into consideration during their biological evaluation.

The chemical modifications made on the Pyridoclax derivatives will necessarily impact their pro-apoptotic activity. In other studies, we had previously evaluated the ability of some oligopyridine analogs to sensitize IGROV1-R10 ovarian cancer cells to siRNAmediated $\mathrm{Bcl}-\mathrm{X}_{\mathrm{L}}$ silencing, and hence, to induce apoptosis through Mcl-1 inhibition. ${ }^{[4,18]}$ From the obtained results, it appeared that some modifications did not affect the activity, whereas others decreased or completely abolished it in comparison with Pyridoclax. In particular, the methyl and styryl hydrophobic motifs situated on the bipyridine core are necessary for the pro-apoptotic activity, as the the bipyridine core itself; the nitrogen present on terminal pyridines also plays an important role whereas the absence of nitrogen on one of the terminal rings does not influence its pro-apoptotic activity. Interestingly, these structureactivity relationships have been added to the summary proposed Figure 3.
Figure 3. Summary of the impact of the structural modifications made on the studied derivatives on their physico-chemical properties in comparison with Pyridoclax (MR29072): = means "no significant influence", \ means "increase" and \, "decrease 
At the present, MR29072, Pyridoclax, is considered as the lead compound of the family of oligopyridines that we studied. In its envisaged therapeutic application, Pyridoclax must inhibit proteinprotein interactions between $\mathrm{Bcl}-2$ proteins control of the Mitochondrial Outer Membrane Permeabilization (MOMP), which leads to downstream caspase to execute apoptosis. Considering this point and our results obtained so far, we have decided to further investigate the membrane insertion property of Pyridoclax.

Interactions between Pyridoclax and lipid monolayer studied at the air-water interface

Results of ellipsometry and surface pressure measurements performed on Pyridoclax (MR29072) used at the concentration of $10 \mu \mathrm{M}$ show that the compound is able to adsorb at the air-HEPES interface, indicating an amphipathic behavior reliable to its chemical structure (Figure 4).

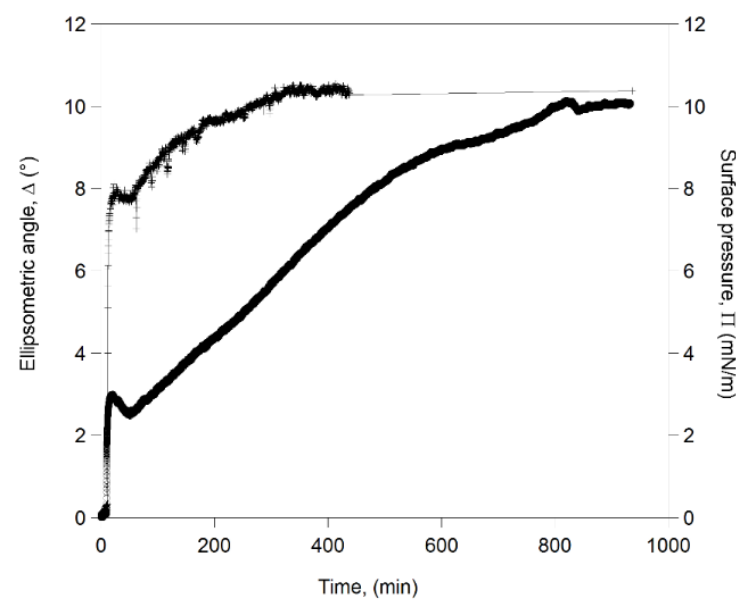

Figure 4. Ellipsometry $(+)$ and surface pressure (o) measurements performed on MR29072 $(10 \mu \mathrm{M})$ at the air-buffer (HEPES $50 \mathrm{mM}+\mathrm{NaCl} 107 \mathrm{mM})$ interface.

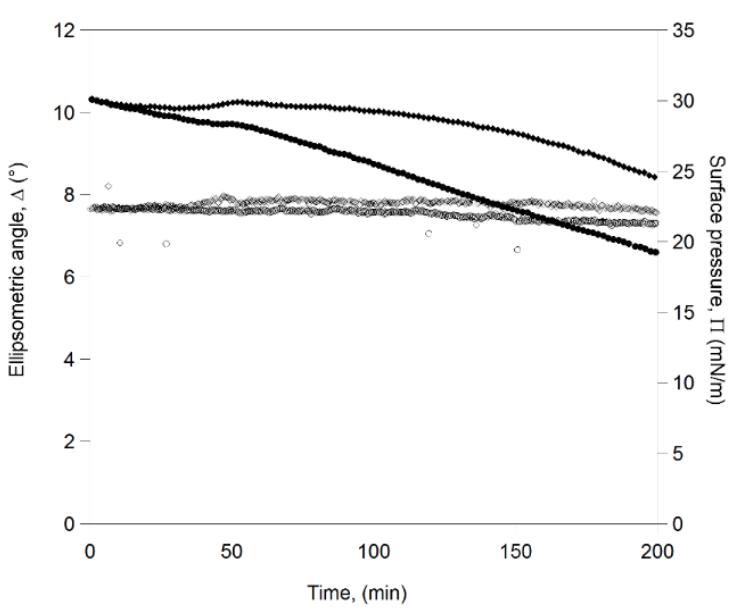

Figure 5. Ellipsometry (empty symbols) and surface pressure (full symbols) kinetic measurements performed on MR29072 in presence of a DOPC:DOPG film spread at the air-buffer (HEPES $50 \mathrm{mM}+\mathrm{NaCl} 107 \mathrm{mM}$ ) interface at initial surface pressure of $30 \mathrm{mN} / \mathrm{m}$ at two concentrations $10 \mu \mathrm{M}$ (ring), and $25 \mu \mathrm{M}$ (diamond).
From ellipsometry measurements, the interfacial monomolecular film seems to reach equilibrium, whereas the increasing surface pressure in time suggests lateral aggregation of the compound at the interface.

From results (Figure 5), at $10 \mu \mathrm{M}$, MR29072 is able to interact within the phospholipid monolayer at a surface pressure (П) around $30 \mathrm{mN} / \mathrm{m}$. Indeed, in presence of MR29072 in the subphase, the ellipsometric angle was constant for $100 \mathrm{~min}$ and then was slowly decreasing while the surface pressure decrease began earlier at $50 \mathrm{~min}$. These physical parameters were stable for the lipid film without Pyridoclax for 6 hours (data not shown). By binding to polar heads, Pyridoclax would create a condensing effect of the DOPC:DOPG monolayer.
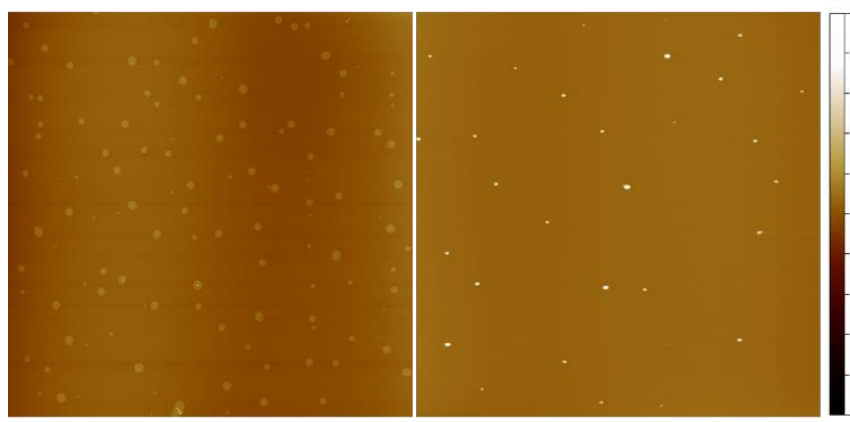

Figure 6. Atomic Force Microscopy (AFM) images of the interfacial films obtained at the end of kinetic interaction between MR29072 (A. 10 or B. $25 \mu \mathrm{M}$ ) and DOPC:DOPG film. The $z$ scale corresponding to the color scale is in the range of -10 to $10 \mathrm{~nm}$ for $\mathbf{A}$. and of -50 to $50 \mathrm{~nm}$ for $\mathbf{B}$. The image size is $40 \mu \mathrm{m}$ $\times 40 \mu \mathrm{m}$.

From observations performed by Atomic Force Microscopy (AFM) after transfer of the interfacial film to freshly cleaved mica sheet (Figure 6.A.), it appears that this interaction is accompanied by the formation of patches regularly dispersed on the images which have a mean height of $2.5 \pm 0.2 \mathrm{~nm}$ and a diameter varying between 200 to $800 \mathrm{~nm}$. The presence of these domains is only observed for the experiment made in presence of the Pyridoclax revealing the presence of the Pyridoclax on the lipid film. The height of each domain is regular, meaning lateral interactions in the film thickness avoiding 3D aggregation.

Increase of the concentration of Pyridoclax to $25 \mu \mathrm{M}$ leads to comparable results in ellipsometry and in surface pressure measurement (Figure 5). However, the decrease of surface pressure and of the ellipsometric angle appear less pronounced, suggesting a more efficient insertion of the Pyridoclax when used at higher concentration. Moreover, as shown by AFM, the organization of the phospholipid film in presence of $25 \mu \mathrm{M}$ Pyridoclax becomes different since the presence of spots with a diameter around to $400 \mathrm{~nm}$ and a mean height of $40 \pm 3 \mathrm{~nm}$ are homogeneously observed throughout the sample (Figure 6.B.). The height could result of local aggregation of the amphipathic molecule forming 3D structures.

The ability of Pyridoclax to induce the formation of phospholipids aggregates contributes to a reorganization of the membrane, as objectified by the CF leakage effect on LUVs formulated without cholesterol. Such effect may contribute to the action mechanism of this anticancer lead. 


\section{Conclusions}

The experimental data generated in the present study on 19 original oligopyridines have permitted to assess relative differences in terms of physico-chemical properties, which could be determinant for their ADME-Tox properties. By this way, the druggability pattern of these oligopyridines of therapeutic interest as potential protein-protein interactions disruptors, and in particular, those of the lead of this family, is more informed: druggability space seems to be limited to 4 aromatic rings, associated to styryl group on a pyridine. Possible direct interactions between the compounds and biological membranes should be considered when their action mechanism will be explored. Further studies are now to plan for detailing in deep the high potential of this library of oligopyridines, being the presented result encouraging and considered as a settled part of the drug discovery and characterization work.

\section{Experimental Section}

\section{Chemical Synthesis}

Commercial reagents were used without additional purification. Only new compounds are described. ${ }^{1} \mathrm{H}$ NMR $(400 \mathrm{MHz})$ and ${ }^{13} \mathrm{C}$ NMR $(100 \mathrm{MHz})$ spectra were recorded on a Bruker 400 spectrometer. Chemical shifts are expressed in parts per million downfield from tetramethylsilane as an internal standard and coupling constants in hertz. Chemical shifts are reported in parts per million (ppm) relative to the solvent resonance. Melting points were recorded using a Kofler bench. Chromatography was carried out on a column using flash silica gel 60 Merck $(0.063-0.200 \mathrm{~mm})$ as the stationary phase. The eluting solvent indicated for each purification was determined by thin layer chromatography (TLC) performed on $0.2 \mathrm{~mm}$ precoated plates of silica gel 60F-264 (Merck) and spots were visualized using an ultraviolet-light lamp. Purities of samples subjected to biological testing were assessed using these two methods and shown to be $\geq 95 \%$. High resolution mass spectra were performed at $70 \mathrm{eV}$ by electronic impact (HRMS/EI) or by positive or negative electrospray (HRMS/ESI) on a Xevo ${ }^{\circledR}$ G2-XS QTof (Waters).

General procedure A for Suzuki-Miyaura coupling reactions: 2-(6-Bromo3-pyridyl)-5-[5-bromo-3-[(E)-styryl]-2-pyridyl]-3-methyl-pyridine 1

To a reaction vessel in a nitrogen atmosphere containing 5-bromo-2-(6iodo-5-methyl-3-pyridyl)-3-[(E)-styryl]pyridine, obtained as reported in the literature, ${ }^{[4]}(0.37 \mathrm{~g}, 0.78 \mathrm{mmol})$ were added 6-bromopyridin-3-ylboronic acid $\quad(0.17 \mathrm{~g}, \quad 0.85 \mathrm{mmol}, \quad 1.1$ equiv), tetrakis(triphenylphosphine)palladium $(0)(0.05 \mathrm{~g}, 0.04 \mathrm{mmol}, 5 \% \mathrm{~mol})$ and aqueous $\mathrm{K}_{3} \mathrm{PO}_{4}(0.41 \mathrm{~g}, 1.9 \mathrm{mmol}, 2.5$ equiv) in 1,4-dioxane $(80 \mathrm{~mL})$. The mixture was stirred at reflux for $3 \mathrm{~h}$, followed by TLC. The mixture was cooled to room temperature, quenched with water and extracted with ethyl acetate $(3 \times 100 \mathrm{~mL})$. The organic layers were collected, washed with brine dried over anhydrous magnesium sulfate, filtered and concentrated under reduced pressure to give the crude compound that was purified by column chromatography ( $c$-hexane/ethyl acetate $4 / 1$ ) to afford $0.28 \mathrm{~g}$ of pure compound 1 as a yellow solid $\left(72 \%\right.$ yield). Mp: $174-178{ }^{\circ} \mathrm{C} .{ }^{1} \mathrm{H}$ NMR $\left(\mathrm{CDCl}_{3}\right) \delta 8.77(\mathrm{~d}, J=1.7 \mathrm{~Hz}, 1 \mathrm{H}), 8.69(\mathrm{~d}, J=2.0 \mathrm{~Hz}, 1 \mathrm{H}), 8.65(\mathrm{~d}, J=$ $2.3 \mathrm{~Hz}, 1 \mathrm{H}), 8.21(\mathrm{~d}, J=2.0 \mathrm{~Hz}, 1 \mathrm{H}), 7.94(\mathrm{~d}, 1 \mathrm{H}), 7.85(\mathrm{dd}, J=8.2,2.4$ $\mathrm{Hz}, 1 \mathrm{H}), 7.62(\mathrm{~d}, J=8.2 \mathrm{~Hz}, 1 \mathrm{H}), 7.44(\mathrm{~d}, J=7.2 \mathrm{~Hz}, 2 \mathrm{H}), 7.40-7.30(\mathrm{~m}$, $3 \mathrm{H}), 7.17-7.04(\mathrm{~m}, 2 \mathrm{H}), 2.48(\mathrm{~s}, 3 \mathrm{H}) .{ }^{13} \mathrm{C} \mathrm{NMR}\left(\mathrm{CDCl}_{3}\right) \delta 154.2,152.1$, $150.4,149.6,148.2,142.0,140.0,139.3,136.6,136.2,135.1,134.14$, $133.9,133.6,131.3,129.0,128.9,127.9,127.1,123.7,120.5,20.1 . M S$ $(\mathrm{ESI}+): m \mid z 508.39\left(\mathrm{M}+\mathrm{H}^{+}\right) ; 510.41\left(\mathrm{M}^{+}+2\right)$.

General procedure for Suzuki-Miyaura coupling (B): 2-[5-Methyl-6-[6-(3pyridyl)-3-pyridyl]-3-pyridyl]-5-(3-pyridyl)-3-[(E)-styryl]pyridine (MR33716) To a reaction vessel in a nitrogen atmosphere containing 2-(6-bromo-3pyridyl)-5-[5-bromo-3-[(E)-styryl]-2-pyridyl]-3-methyl-pyridine 1 (0.15 g,
$0.30 \mathrm{mmol})$ were added 3-pyridylboronic acid $(0.08 \mathrm{~g}, 0.66 \mathrm{mmol}, 2.2$ equiv), tetrakis(triphenylphosphine)palladium(0) $(0.04 \mathrm{~g}, 0.03 \mathrm{mmol}, 10 \%$ $\mathrm{mol})$ and aqueous $\mathrm{K}_{3} \mathrm{PO}_{4}(0.32 \mathrm{~g}, 0.15 \mathrm{mmol}, 5.0$ equiv) in 1,4-dioxane $(60$ $\mathrm{mL}$ ). The mixture was stirred at reflux for $2 \mathrm{~h}$, followed by TLC. The mixture was cooled to room temperature, quenched with water and extracted with ethyl acetate $(3 \times 100 \mathrm{~mL})$. The organic layers were collected, washed with brine, dried over anhydrous magnesium sulfate, filtered and concentrated under reduced pressure to give the crude compound that was purified by flash chromatography on silica gel $\left(\mathrm{CH}_{2} \mathrm{Cl}_{2} /\right.$ Methanol 99/1) to afford 0.09 $\mathrm{g}$ of pure compound MR33716 as a light yellow solid (57\% yield). Mp: 162 $164{ }^{\circ} \mathrm{C} .{ }^{1} \mathrm{H} \mathrm{NMR}\left(\mathrm{CDCl}_{3}\right) \delta 9.27(\mathrm{dd}, J=2.3,0.9 \mathrm{~Hz}, 1 \mathrm{H}), 9.02(\mathrm{dd}, J=2.3$, $0.9 \mathrm{~Hz}, 1 \mathrm{H}), 8.97(\mathrm{dd}, J=2.3,0.9 \mathrm{~Hz}, 1 \mathrm{H}), 8.88(\mathrm{dd}, J=2.1,0.6 \mathrm{~Hz}, 1 \mathrm{H})$ $8.87(\mathrm{~d}, J=2.2 \mathrm{~Hz}, 1 \mathrm{H}), 8.71$ (dd, $J=4.8,1.6 \mathrm{~Hz}, 1 \mathrm{H}$ ), 8.68 (dd, $J=4.8$, $1.7 \mathrm{~Hz}, 1 \mathrm{H}$ ), 8.40 (ddd, $J=7.9,2.4,1.7 \mathrm{~Hz}, 1 \mathrm{H}), 8.24(\mathrm{~d}, J=2.2 \mathrm{~Hz}, 1 \mathrm{H})$, 8.12 (dd, $J=8.1,2.3 \mathrm{~Hz}, 1 \mathrm{H}$ ), 8.05 (dd, $J=2.2,0.8 \mathrm{~Hz}, 1 \mathrm{H}$ ), 8.01 (ddd, $J$ $=7.9,2.4,1.6 \mathrm{~Hz}, 1 \mathrm{H}), 7.90(\mathrm{dd}, J=8.2,0.9 \mathrm{~Hz}, 1 \mathrm{H}), 7.49-7.46(\mathrm{~m}, 3 \mathrm{H})$, 7.44 (ddd, $J=7.9,4.8,0.9 \mathrm{~Hz}, 1 \mathrm{H}$ ), 7.36 (t, $J=7.4 \mathrm{~Hz}, 2 \mathrm{H}), 7.30(\mathrm{~m}, 1 \mathrm{H})$, 7.29 (s, 1H), 7.25 (s, 1H), $2.56(\mathrm{~s}, 3 \mathrm{H}) .{ }^{13} \mathrm{C} \mathrm{NMR}\left(\mathrm{CDCl}_{3}\right) \delta 155.0,154.4$ 153.5, 150.4, 150.2, 149.7, 148.6, 148.4, 148.3, 147.1, 140.1, 137.9, 136.5, 135.1, 134.6, 134.6, 134.3, 133.3, 133.2, 133.1, 132.8, 132.2, 131.4, 129.0, 128.7, 127.0, 124.8, 124.0, 123.8, 120.2, 20.3. MS (ESI+): $m \mid z 504.49$ (M $\left.+\mathrm{H}^{+}\right), 505.53\left(\mathrm{M}+2 \mathrm{H}^{+}\right)$. HRMS (ES): $\mathrm{m} / z$ calcd for $\mathrm{C}_{34} \mathrm{H}_{25} \mathrm{~N}_{5}[\mathrm{M}+\mathrm{H}]^{+}$ 504.2188 , found 504.2191

\section{5-Bromo-2-[6-(6-iodo-3-pyridyl)-5-methyl-3-pyridyl]-3-[(E)-styryl]pyridine} terpyridine 2

To a microwave vial containing 2-(6-bromo-3-pyridyl)-5-[5-bromo-3-[(E)styryl]-2-pyridyl]-3-methylpyridine $1(0.28 \mathrm{~g}, 0.56 \mathrm{mmol})$ were added $\mathrm{Nal}$ (0.84 g, $5.60 \mathrm{mmol}, 10.0$ equiv) and $\mathrm{CH}_{3} \mathrm{COCl}(0.09 \mathrm{~g}, 1.12 \mathrm{mmol}, 2.0$ equiv) in acetonitrile $(15 \mathrm{~mL})$. The halogen exchange was carried out under microwave irradiation at $100^{\circ} \mathrm{C}$ for $1 \mathrm{~h}(400 \mathrm{~W})$. The reaction was carefully quenched by addition of saturated aqueous $\mathrm{NaHCO}_{3}$ solution until $\mathrm{pH} 8$. The solution was extracted with ethyl acetate $(3 \times 100 \mathrm{~mL})$ and washed with saturated aqueous $\mathrm{NaHSO}_{3}$ solution. The organic layers were collected, washed with brine, dried over anhydrous magnesium sulfate, filtered and concentrated under reduced pressure to give $0.29 \mathrm{~g}$ of the crude compound 2 (94\% yield, calculated by ${ }^{1} \mathrm{H}$ NMR) as yellow solid that can be used in the next reaction without further purification. ${ }^{1} \mathrm{H}$ NMR $\left(\mathrm{CDCl}_{3}\right) \delta 8.77(\mathrm{~d}, J=1.9 \mathrm{~Hz}, 1 \mathrm{H}), 8.68(\mathrm{~d}, J=2.1 \mathrm{~Hz}, 1 \mathrm{H}), 8.64(\mathrm{~d}, J=$ $2.3 \mathrm{~Hz}, 1 \mathrm{H}), 8.19(\mathrm{~d}, J=2.1 \mathrm{~Hz}, 1 \mathrm{H}), 7.93(\mathrm{~d}, J=1.6 \mathrm{~Hz}, 1 \mathrm{H}), 7.85(\mathrm{~d}, J=$ $8.1 \mathrm{~Hz}, 1 \mathrm{H}), 7.62(\mathrm{dd}, J=8.1,2.5 \mathrm{~Hz}, 1 \mathrm{H}), 7.43(\mathrm{~m}, 2 \mathrm{H}), 7.37-7.28(\mathrm{~m}$, $4 \mathrm{H}), 7.10(\mathrm{q}, J=16.2 \mathrm{~Hz}, 2 \mathrm{H}), 2.45(\mathrm{~s}, 3 \mathrm{H}) .{ }^{13} \mathrm{C} \mathrm{NMR}\left(\mathrm{CDCl}_{3}\right) \delta 153.90$ $153.47,150.81,148.56,148.19,141.10,140.03,139.40,136.65,136.23$, $135.33,134.50,133.94,133.12,131.09,129.01,128.90,127.91,127.05$ 119.98, 117.50, 19.90. MS (ESI+): $m \mid z 554.36\left(\mathrm{M}+\mathrm{H}^{+}\right), 556.33\left(\mathrm{M}^{+}+2\right)$, $557.32\left(\mathrm{M}^{+}+3\right)$.

\section{2-[6-(6-Bromo-3-pyridyl)-3-pyridyl]-5-[5-bromo-3-[(E)-styryl]-2-pyridyl]-3-} methyl-pyridine 3

To a reaction vessel in a nitrogen atmosphere containing 5-bromo-2-[6-(6iodo-3-pyridyl)-5-methyl-3-pyridyl]-3-[(E)-styryl] pyridine $2(0.29 \mathrm{~g}, 0.53$ $\mathrm{mmol}$ ) were added 6-bromopyridin-3-ylboronic acid $(0.12 \mathrm{~g}, 0.58 \mathrm{mmol}$, 1.1 equiv), tetrakis(triphenylphosphine)palladium $(0)(0.03 \mathrm{~g}, 0.03, \mathrm{mmo}$ $5 \% \mathrm{~mol})$ and aqueous $\mathrm{K}_{3} \mathrm{PO}_{4}(0.28 \mathrm{~g}, 1.33 \mathrm{mmol}, 2.5$ equiv) in 1,4-dioxane $(50 \mathrm{~mL})$ and the procedure $\boldsymbol{A}$ was performed. The mixture was stirred at reflux for $3 \mathrm{~h}$ following by TLC the consumption of starting material. The residue was purified by chromatography on silica gel (c-hexane/ethyl acetate $=4 / 1)$ to afford $0.13 \mathrm{~g}$ of pure compound 3 as a yellow solid $(42 \%$ yield). mp: $206-208{ }^{\circ} \mathrm{C} .{ }^{1} \mathrm{H}$ NMR $\left(\mathrm{CDCl}_{3}\right) \delta 9.02(\mathrm{~d}, J=2.0 \mathrm{~Hz}, 1 \mathrm{H}), 8.99$ (d, $1 \mathrm{H}$ ), $8.81(\mathrm{~d}, 1 \mathrm{H}), 8.70$ (d, $J=2.0 \mathrm{~Hz}, 1 \mathrm{H}$ ), 8.28 (dd, $J=8.3,2.5 \mathrm{~Hz}$, $1 \mathrm{H}), 8.22(\mathrm{~d}, J=1.8 \mathrm{~Hz}, 1 \mathrm{H}), 8.11(\mathrm{dd}, J=8.2,2.1 \mathrm{~Hz}, 1 \mathrm{H}), 7.97(\mathrm{~d}, J=$ $1.8 \mathrm{~Hz}, 1 \mathrm{H}), 7.87(\mathrm{~d}, J=8.2 \mathrm{~Hz}, 1 \mathrm{H}), 7.62(\mathrm{~d}, J=8.3 \mathrm{~Hz}, 1 \mathrm{H}), 7.45(\mathrm{~d}, J=$ $7.2 \mathrm{~Hz}, 2 \mathrm{H}), 7.40-7.24(\mathrm{~m}, 3 \mathrm{H}), 7.22-7.07(\mathrm{~m}, 2 \mathrm{H}), 2.57$ (s, 3H). ${ }^{13} \mathrm{C}$ NMR $\left(\mathrm{CDCl}_{3}\right) \delta 154.8,153.0,152.2,150.4,149.6,148.6,148.1,142.8,139.9$, $137.9,136.9,136.6,136.2,135.3,133.9,133.8,133.5,131.3,128.9,128.8$, 128.2, 127.0, 123.7, 120.4, 119.9, 20.2. MS (ESI+): $m \mid z 585.36\left(\mathrm{M}+\mathrm{H}^{+}\right)$, $587.38\left(\mathrm{M}^{+}+2\right)$. 
2-[5-Methyl-6-[6-[6-(3-pyridyl)-3-pyridyl]-3-pyridyl]-3-pyridyl]-5-(3-pyridyl)3-[(E)-styryl] pyridine (MR33715)

To a reaction vessel in a nitrogen atmosphere containing 2-[6-(6-bromo-3pyridyl)-3-pyridyl]-5-[5-bromo-3-[(E)-styryl]-2-pyridyl]-3-methyl-pyridine 3 $(0.13 \mathrm{~g}, 0.22 \mathrm{mmol})$ were added 3-pyridylboronic acid $(0.06 \mathrm{~g}, 0.48 \mathrm{mmol}$, 2.2 equiv), tetrakis(triphenylphosphine)palladium $(0)(0.03 \mathrm{~g}, 0.02 \mathrm{mmol}$, $10 \% \mathrm{~mol})$ and aqueous $\mathrm{K}_{3} \mathrm{PO}_{4}(0.23 \mathrm{~g}, 0.11 \mathrm{mmol}, 5.0$ equiv) in $1,4-$ dioxane $(50 \mathrm{~mL})$ and the procedure $\boldsymbol{B}$ was performed. The mixture was stirred at reflux for $3 \mathrm{~h}$ following by TLC the consumption of starting material. The residue was purified by flash chromatography on silica gel $\left(\mathrm{CH}_{2} \mathrm{Cl}_{2} /\right.$ Methanol 99/1) to afford $0.07 \mathrm{~g}$ of pure compound MR33715 as a white solid $\left(51 \%\right.$ yield). Mp: $240{ }^{\circ} \mathrm{C} .{ }^{1} \mathrm{H}$ NMR $\left(\mathrm{CDCl}_{3}\right) \delta 9.39$ (d, $J=2.2$ $\mathrm{Hz}, 1 \mathrm{H}), 9.30(\mathrm{~s}, 1 \mathrm{H}), 9.05(\mathrm{~d}, J=2.2 \mathrm{~Hz}, 1 \mathrm{H}), 8.99(\mathrm{~d}, J=2.4 \mathrm{~Hz}, 1 \mathrm{H})$, $8.90(\mathrm{~d}, J=2.2 \mathrm{~Hz}, 1 \mathrm{H}), 8.89(\mathrm{~d}, J=2.2 \mathrm{~Hz}, 1 \mathrm{H}), 8.73(\mathrm{dd}, J=4.8,1.6 \mathrm{~Hz}$, $1 \mathrm{H}$ ), 8.76-8.67 (m, 1H), 8.55 (dd, $J=8.2,2.3 \mathrm{~Hz}, 1 \mathrm{H}$ ), 8.43 (dt, $J=8.0$, $1.9 \mathrm{~Hz}, 1 \mathrm{H}), 8.26(\mathrm{~d}, J=2.2 \mathrm{~Hz}, 1 \mathrm{H}), 8.16(\mathrm{dd}, J=8.1,2.3 \mathrm{~Hz}, 1 \mathrm{H}), 8.07$ $(\mathrm{d}, J=2.1 \mathrm{~Hz}, 1 \mathrm{H}), 8.03(\mathrm{dt}, J=7.9,1.9 \mathrm{~Hz}, 1 \mathrm{H}), 7.97(\mathrm{~d}, J=8.1 \mathrm{~Hz}, 1 \mathrm{H})$, $7.92(\mathrm{~d}, J=8.3 \mathrm{~Hz}, 1 \mathrm{H}), 7.51-7.48(\mathrm{~m}, 3 \mathrm{H}), 7.47-7.44(\mathrm{~m}, 1 \mathrm{H}), 7.40-7.35$ $(\mathrm{m}, 2 \mathrm{H}), 7.33-7.29(\mathrm{~m}, 1 \mathrm{H}), 7.28(\mathrm{~s}, 1 \mathrm{H}), 7.27(\mathrm{~s}, 1 \mathrm{H}), 2.59(\mathrm{~s}, 3 \mathrm{H}) .{ }^{13} \mathrm{C}$ NMR $\left(\mathrm{CDCl}_{3}\right) \delta 155.1,154.9,153.8,153.5,150.4,150.2,149.7,148.6$, $148.4,148.3,148.3,147.0,140.0,137.8,136.4,135.5,135.1,134.5,134.4$ $134.3,133.6,133.2,133.1,133.0,132.7,132.1,131.3,128.9,128.6,126.9$ $124.7,123.9,123.7,120.5,120.0,20.2$. MS (ESI+): $m \mid z 581.60\left(\mathrm{M}+\mathrm{H}^{+}\right)$, $582.63\left(\mathrm{M}+2 \mathrm{H}^{+}\right)$. HRMS (ES): $\mathrm{m} / z$ calcd for $\mathrm{C}_{39} \mathrm{H}_{28} \mathrm{~N}_{6}[\mathrm{M}+\mathrm{H}]^{+} 581.2454$, found 581.2462 .

\section{2,5-Bis(3-pyridyl)-3-[(E)-styryl]pyridine (MR29063)}

To a reaction vessel in a nitrogen atmosphere containing $(E)$-5-bromo-2chloro-3-styrylpyridine (obtained as reported in Gloaguen et al. $\left.{ }^{[4]}\right)(0.40 \mathrm{~g}$, $1.4 \mathrm{mmol}$ ) were added 3-pyridylboronic acid $(0.42 \mathrm{~g}, 3.40 \mathrm{mmol}, 2.5$ equiv), tetrakis(triphenylphosphine)palladium $(0)(0.16 \mathrm{~g}, 0.14 \mathrm{mmol}, 10 \% \mathrm{~mol})$ and aqueous $\mathrm{Na}_{2} \mathrm{CO}_{3}(0.72 \mathrm{~g}, 6.5 \mathrm{mmol}, 5.0$ equiv, ) in 1,4-dioxane (150 $\mathrm{mL}$ ) and the procedure $\boldsymbol{B}$ was performed. The mixture was stirred at reflux for $20 \mathrm{~h}$ following by TLC the consumption of starting material. The residue was purified by chromatography on silica gel $\left(\mathrm{CH}_{2} \mathrm{Cl}_{2} /\right.$ Methanol $\left.98 / 2\right)$ to afford $0.28 \mathrm{~g}$ of pure compound MR29063 as a white solid (61\% yield). Mp: $119{ }^{\circ} \mathrm{C} .{ }^{1} \mathrm{H}$ NMR $\left(\mathrm{CDCl}_{3}\right) \delta 8.96(\mathrm{~d}, J=1.9 \mathrm{~Hz}, 1 \mathrm{H}), 8.95(\mathrm{~d}, J=1.9$ $\mathrm{Hz}, 1 \mathrm{H}), 8.85(\mathrm{~d}, J=1.9 \mathrm{~Hz}, 1 \mathrm{H}), 8.70(\mathrm{~d}, J=4.0 \mathrm{~Hz}, 2 \mathrm{H}), 8.21(\mathrm{~d}, J=1.9$ $\mathrm{Hz}, 1 \mathrm{H}), 8.04$ (dt, $J=7.8,1.9 \mathrm{~Hz}, 1 \mathrm{H}), 7.99(\mathrm{dt}, J=7.8,1.9 \mathrm{~Hz}, 1 \mathrm{H}), 7.48$ (m, 2H), 7.44 (d, $J=7.8 \mathrm{~Hz}, 2 \mathrm{H}), 7.35(\mathrm{t}, J=7.8 \mathrm{~Hz}, 2 \mathrm{H}), 7.30$ (d, $J=7.8$ $\mathrm{Hz}, 1 \mathrm{H}), 7.21(\mathrm{~d}, J=16.6 \mathrm{~Hz}, 1 \mathrm{H}), 7.14(\mathrm{~d}, J=16.6 \mathrm{~Hz}, 1 \mathrm{H}) .{ }^{13} \mathrm{C} N M R$ $\left(\mathrm{CDCl}_{3}\right) \delta 153.8,150.5,149.6,149.5,148.1,146.8,137.1,136.3,134.9$, 134.4, 133.0, 132.9, 132.8, 132.5, 131.9, 128.8, 128.5, 126.8, 124.6, 123.8, 123.2. MS $(\mathrm{ESI}+): m \mid z 336.58\left(\mathrm{M}+\mathrm{H}^{+}\right), 337.57\left(\mathrm{M}+2 \mathrm{H}^{+}\right)$. HRMS (ES): $\mathrm{m} / \mathrm{z}$ calcd for $\mathrm{C}_{23} \mathrm{H}_{17} \mathrm{~N}_{3}[\mathrm{M}+\mathrm{H}]^{+} 336.4123$, found 336.2298 .

\section{3'-Methyl-3,2':5',3"-terpyridine (MR33714)}

To a reaction vessel in a nitrogen atmosphere containing 2,5-dibromo-3methylpyridine $(3.0 \mathrm{~g}, 12.7 \mathrm{mmol})$ were added 3-pyridylboronic acid $(3.11$ g, $25.30 \mathrm{mmol}, 2.0$ equiv), tetrakis(triphenylphosphine)palladium(0) (1.46 $\mathrm{g}, 1.27 \mathrm{mmol}, 10 \% \mathrm{~mol})$ and aqueous $\mathrm{K}_{2} \mathrm{CO}_{3}(8.73 \mathrm{~g}, 63.30 \mathrm{mmol}, 5.0$ equiv) in 1,4-dioxane $(250 \mathrm{~mL})$ and the procedure $\boldsymbol{A}$ was performed. The mixture was stirred at reflux for $24 \mathrm{~h}$ following by TLC the consumption of starting material. The mixture was cooled at room temperature and quenched with water and extracted with ethyl acetate $(3 \times 200 \mathrm{~mL})$. The crude compound was filtered on Gooch and washed with $100 \mathrm{~mL}$ of $c$ hexane/ethyl acetate $6 / 4$ solution, affording $2.75 \mathrm{~g}$ of pure compound MR33714 as a light brown solid (65\% yield). Mp: $152-156{ }^{\circ} \mathrm{C} .{ }^{1} \mathrm{H}$ NMR $\left(400 \mathrm{MHz}, \mathrm{CDCl}_{3}\right) \delta 8.90(\mathrm{~d}, J=1.8 \mathrm{~Hz}, 1 \mathrm{H}), 8.86(\mathrm{~d}, J=1.8 \mathrm{~Hz}, 1 \mathrm{H}), 8.79$ (d, $J=2.2 \mathrm{~Hz}, 1 \mathrm{H}), 8.68$ (dd, $J=4.7,1.0 \mathrm{~Hz}, 2 \mathrm{H}), 7.97-7.92(\mathrm{~m}, 2 \mathrm{H}), 7.83$ (d, $J=2.2 \mathrm{~Hz}, 1 \mathrm{H}), 7.47-7.42(\mathrm{~m}, 2 \mathrm{H}), 2.17$ (s, 3H). ${ }^{13} \mathrm{C} \mathrm{NMR}\left(\mathrm{CDCl}_{3}\right) \delta$ 155.2, 149.9, 149.5, 149.3, 148.2, 145.7, 137.2, 136.5, 135.7, 134.4, 133.1 132.6, 131.5, 123.8, 123.3, 20.1. MS (ESI+): $m \mid z 248.45\left(\mathrm{M}+\mathrm{H}^{+}\right), 249.53$ $\left(\mathrm{M}+2 \mathrm{H}^{+}\right)$. HRMS (ES): $\mathrm{m} / \mathrm{z}$ calcd for $\mathrm{C}_{16} \mathrm{H}_{13} \mathrm{~N}_{3}[\mathrm{M}+\mathrm{H}]^{+} 248.1188$, found 248.1190

\section{(E)-2-Chloro-3-styrylpyridine 4}

To a reaction vessel in a nitrogen atmosphere containing 3-iodo-2chloropyridine $(0.92 \mathrm{~g}, 3.80 \mathrm{mmol})$ were added $(E)$-styrylboronic acid $(1.1$ equiv, $0.62 \mathrm{~g}, 4.20 \mathrm{mmol}$ ), tetrakis(triphenylphosphine)palladium $(0)(0.22$ $\mathrm{g}, 0.19 \mathrm{mmol}, 5 \% \mathrm{~mol})$ and aqueous $\mathrm{K}_{3} \mathrm{PO}_{4}(2.5$ equiv, $2.03 \mathrm{~g}, 9.56 \mathrm{mmol})$ in dioxane $(200 \mathrm{~mL})$ and the procedure $\boldsymbol{A}$ was performed. The mixture was stirred at reflux for $3 \mathrm{~h}$ following by TLC the consumption of starting material. The residue was purified by chromatography on silica gel (cyclohexane/ethyl acetate $=99 / 1$ ) to afford $0.366 \mathrm{~g}$ of pure compound as a white solid (52\% yield). Mp: $94-96{ }^{\circ} \mathrm{C} .{ }^{1} \mathrm{H}$ NMR $\left(\mathrm{CDCl}_{3}\right) \delta 8.29$ (dd, $J=$ $4.7,1.8 \mathrm{~Hz}, 1 \mathrm{H}), 7.97(\mathrm{dd}, J=7.7,1.8 \mathrm{~Hz}, 1 \mathrm{H}), 7.55(\mathrm{~d}, J=7.3 \mathrm{~Hz}, 2 \mathrm{H})$, 7.45-7.30 (m, 3H), 7.25 (dd, $J=7.7,4.7 \mathrm{~Hz}, 1 \mathrm{H}), 7.09(\mathrm{~d}, J=16.3 \mathrm{~Hz}, 1 \mathrm{H})$; ${ }^{13} \mathrm{C} \mathrm{NMR}\left(\mathrm{CDCl}_{3}\right) \delta 150.3,148.2,136.5,134.7,133.4,132.3,129.0,128.8$, 127.1, 123.2, 122.9. MS (ESI+): $m \mid z 216.38\left(\mathrm{M}+\mathrm{H}^{+}\right), 218.35\left(\mathrm{M}^{+}+2\right)$.

\section{(E)-5'-Methyl-3-styryl-2,3'-bipyridine (MR33717)}

To a reaction vessel in a nitrogen atmosphere containing $(E)$-2-chloro-3styrylpyridine 4 (0.37 g, $1.69 \mathrm{mmol})$ were added 5-methylpyridin-3ylboronic acid (1.5 equiv, $0.35 \mathrm{~g}, \quad 2.53 \mathrm{mmol})$, tetrakis(triphenylphosphine)palladium( 0$)(0.098 \mathrm{~g}, 0.08 \mathrm{mmol}, 5 \% \mathrm{~mol})$ and aqueous $\mathrm{K}_{3} \mathrm{PO}_{4}(0.897 \mathrm{~g}, 4.22 \mathrm{mmol}, 2.5$ equiv) in 1,4-dioxane (40 $\mathrm{mL}$ ) and the procedure $\boldsymbol{A}$ was performed. The mixture was stirred at reflux for $3 \mathrm{~h}$ following by TLC the consumption of starting material. The residue was purified by chromatography on silica gel (c-hexane/ethyl acetate 7/3) to afford $0.30 \mathrm{~g}$ of pure compound MR33717 as a beige oil (65\% yield). ${ }^{1} \mathrm{H}$ $\operatorname{NMR}\left(\mathrm{CDCl}_{3}\right) \delta 8.71(\mathrm{~d}, J=1.8 \mathrm{~Hz}, 1 \mathrm{H}), 8.66(\mathrm{dd}, J=4.7,1.6 \mathrm{~Hz}, 1 \mathrm{H})$, $8.56(\mathrm{~m}, 1 \mathrm{H}), 8.07(\mathrm{dd}, J=8.0,1.5 \mathrm{~Hz}, 1 \mathrm{H}), 7.86(\mathrm{~m}, 1 \mathrm{H}), 7.45(\mathrm{~d}, J=1.5$ $\mathrm{Hz}, 1 \mathrm{H}), 7.43(\mathrm{~s}, 1 \mathrm{H}), 7.39-7.33(\mathrm{~m}, 3 \mathrm{H}), 7.32-7.29(\mathrm{~m}, 1 \mathrm{H}), 7.14(\mathrm{~s}, 2 \mathrm{H})$, $2.45(\mathrm{~s}, 3 \mathrm{H}) .{ }^{13} \mathrm{C} \mathrm{NMR}\left(\mathrm{CDCl}_{3}\right) \delta 154.5,150.0,148.7,147.8,137.8,136.8$, 135.2, 134.2, 133.1, 132.2, 131.8, 128.9, 128.4, 126.9, 125.2, 123.1, 18.6 . MS $(\mathrm{ESI}+): \mathrm{mlz} 273.54\left(\mathrm{M}+\mathrm{H}^{+}\right), 274.53\left(\mathrm{M}+2 \mathrm{H}^{+}\right)$. HRMS (ES): $\mathrm{m} / \mathrm{z}$ calcd for $\mathrm{C}_{19} \mathrm{H}_{16} \mathrm{~N}_{2}[\mathrm{M}+\mathrm{H}]^{+} 273.1392$, found 273.1403 .

\section{2-Bromo-5-(5-bromo-3-methyl-2-pyridyl)-3-methyl-pyridine 5}

To a reaction vessel in a nitrogen atmosphere containing 5-bromo-2-iodo3-methyl-pyridine $(0.700 \mathrm{~g}, 2.3 \mathrm{mmol})$ were added 6-bromo-5-methyl-3pyridylboronic acid $(0.56 \mathrm{~g}, 2.80 \mathrm{mmol}, 1.3$ equiv) tetrakis(triphenylphosphine)palladium(0) $(0.13 \mathrm{~g}, 0.12 \mathrm{mmol}, 5 \% \mathrm{~mol})$ and aqueous $\mathrm{Na}_{2} \mathrm{CO}_{3}(0.62 \mathrm{~g}, 5.90 \mathrm{mmol}, 2.5$ equiv) in 1,4-dioxane $(10 \mathrm{~mL})$ and the procedure $\boldsymbol{B}$ was performed. The residue was purified by chromatography on silica gel (c-hexane/ethyl acetate 95/5) to afford 0.62 $\mathrm{g}$ of pure compound $\mathbf{5}$ as a yellow solid $\left(77 \%\right.$ yield). Mp: $130{ }^{\circ} \mathrm{C} .{ }^{1} \mathrm{H}$ NMR $\left(\mathrm{CDCl}_{3}\right) \delta 8.60(\mathrm{~d}, J=1.9 \mathrm{~Hz}, 1 \mathrm{H}), 8.35(\mathrm{~d}, J=1.9 \mathrm{~Hz}, 1 \mathrm{H}), 7.78(\mathrm{~d}, J=$ $1.9 \mathrm{~Hz}, 1 \mathrm{H}), 7.72(\mathrm{~d}, J=1.9 \mathrm{~Hz}, 1 \mathrm{H}), 2.46(\mathrm{~s}, 3 \mathrm{H}), 2.38(\mathrm{~s}, 3 \mathrm{H}) .{ }^{13} \mathrm{C}$ NMR $\left(\mathrm{CDCl}_{3}\right) \delta 152.8,148.5,147.0,144.5,141.1,139.2,135.0,134.5,133.0$, 119.9, 22.0, 19.8. MS (ESI+): $m \mid z 342.31\left(\mathrm{M}+\mathrm{H}^{+}\right), 344.78\left(\mathrm{M}^{+}+2\right)$.

\section{5-Bromo-2-(6-iodo-5-methyl-3-pyridyl)-3-methyl-pyridine 6}

To a reaction vessel containing 2-bromo-5-(5-bromo-3-methyl-2-pyridyl)3-methyl-pyridine 5 (1.8 g, $5.3 \mathrm{mmol})$ were added $\mathrm{Nal}(1.97 \mathrm{~g}, 13.10 \mathrm{mmol}$, 2.5 equiv) and $\mathrm{CH}_{3} \mathrm{COCl}(0.62 \mathrm{~g}, 7.90 \mathrm{mmol}, 1.5$ equiv) in acetonitrile (100 $\mathrm{mL}$ ). The mixture was stirred at reflux for $4 \mathrm{~h}$, cooled at room temperature quenched with water and extracted with ethyl acetate $(3 \times 100 \mathrm{~mL})$. The organic layers were collected, washed with brine, dried over anhydrous magnesium sulfate, filtered and concentrated under reduced pressure to give the crude compound which was put in the reaction conditions described upon and stirred at reflux for $4 \mathrm{~h}$. The reaction was carefully quenched by addition of saturated aqueous $\mathrm{NaHCO}_{3}$ solution until $\mathrm{pH}-8$. The solution was extracted with ethyl acetate $(3 \times 100 \mathrm{~mL})$ and washed with saturated aqueous $\mathrm{NaHSO}_{3}$ solution. The organic layers were collected, washed with brine, dried over anhydrous magnesium sulfate, filtered and concentrated under reduced pressure to give $0.29 \mathrm{~g}$ of the crude compound which was purified by chromatography on silica gel ( $c$ hexane/ethyl acetate 9/1) to afford $1.91 \mathrm{~g}$ of pure compound 6 as a beige solid (93\% yield). Mp: $128^{\circ} \mathrm{C} .{ }^{1} \mathrm{H} \mathrm{NMR}\left(\mathrm{CDCl}_{3}\right) \delta 8.58(\mathrm{~d}, J=1.9 \mathrm{~Hz}, 1 \mathrm{H})$, $8.31(\mathrm{~d}, J=1.9 \mathrm{~Hz}, 1 \mathrm{H}), 7.77(\mathrm{~d}, J=1.9 \mathrm{~Hz}, 1 \mathrm{H}), 7.62(\mathrm{~d}, J=1.9 \mathrm{~Hz}, 1 \mathrm{H})$, $2.46(\mathrm{~s}, 3 \mathrm{H}), 2.38(\mathrm{~s}, 3 \mathrm{H}) .{ }^{13} \mathrm{C} \mathrm{NMR}\left(\mathrm{CDCl}_{3}\right) \delta 152.9,148.5,147.4,141.1$, 
139.1, 137.1, 134.7, 133.0, 125.0, 119.9, 26.2, 19.8. MS (ESI+): $m \mid z$ $389.36\left(\mathrm{M}+\mathrm{H}^{+}\right), 392.31\left(\mathrm{M}^{+}+2\right)$.

\section{5-Bromo-2-[6-(6-bromo-5-methyl-3-pyridyl)-5-methyl-3-pyridyl]-3-methyl- pyridine 7}

To a reaction vessel in a nitrogen atmosphere containing 5-bromo-2-(6iodo-5-methyl-3-pyridyl)-3-methyl-pyridine $6(1.7 \mathrm{~g}, 4.40 \mathrm{mmol})$ were added 6-bromo-5-methyl-3-pyridylboronic acid $(1.13 \mathrm{~g}, 5.20 \mathrm{mmol}, 1.3$ equiv), tetrakis(triphenylphosphine)palladium(0) $(0.25 \mathrm{~g}, 0.22 \mathrm{mmol}, 5 \%$ $\mathrm{mol}$ ) and aqueous $\mathrm{Na}_{2} \mathrm{CO}_{3}(1.16 \mathrm{~g}, 10.90 \mathrm{mmol}, 2.5$ equiv) in 1,4-dioxane $(150 \mathrm{~mL})$ and the procedure $\boldsymbol{A}$ was performed. The residue was purified by chromatography on silica gel (c-hexane/ethyl acetate $9 / 1$ ) to afford 1.40 $\mathrm{g}$ of pure compound 7 as a yellow solid $\left(75 \%\right.$ yield). Mp: $141^{\circ} \mathrm{C}$. ${ }^{1} \mathrm{H}$ NMR $\left(\mathrm{CDCl}_{3}\right) \delta 8.69(\mathrm{~d}, J=1.9 \mathrm{~Hz}, 1 \mathrm{H}), 8.62(\mathrm{~d}, J=1.9 \mathrm{~Hz}, 1 \mathrm{H}), 8.42(\mathrm{~d}, J=$ $1.9 \mathrm{~Hz}, 1 \mathrm{H}), 7.79-7.81(\mathrm{~m}, 3 \mathrm{H}), 2.48(\mathrm{~s}, 3 \mathrm{H}), 2.46(\mathrm{~s}, 3 \mathrm{H}), 2.44(\mathrm{~s}, 3 \mathrm{H}) .{ }^{13} \mathrm{C}$ NMR $\left(\mathrm{CDCl}_{3}\right) \delta 153.9,153.5,148.5,147.3,147.2,144.3,141.0,139.4$, $139.3,135.2,134.9,134.5,133.1,131.0,119.8,22.0,20.0,19.9 . \mathrm{MS}$ $(\mathrm{ESI}+): m \mid z 434.52\left(\mathrm{M}+\mathrm{H}^{+}\right), 436.44\left(\mathrm{M}^{+}+2\right)$.

\section{3-Methyl-2-[5-methyl-6-[5-methyl-6-(3-pyridyl)-3-pyridyl]-3-pyridyl]-5-(3-} pyridyl)pyridine (MR29015)

To a reaction vessel in a nitrogen atmosphere containing 5-bromo-2-[6-(6bromo-5-methyl-3-pyridyl)-5-methyl-3-pyridyl]-3-methyl-pyridine 7 (0.39 g, $0.90 \mathrm{mmol}$ ) were added 3-pyridylboronic acid $(0.29 \mathrm{~g}, 2.3 \mathrm{mmol}, 2.5$ equiv), tetrakis(triphenylphosphine)palladium $(0)(0.10 \mathrm{~g}, 0.09 \mathrm{mmol}, 10 \% \mathrm{~mol})$ and aqueous $\mathrm{Na}_{2} \mathrm{CO}_{3}$ (5.0 equiv, $0.48 \mathrm{~g}, 4.60 \mathrm{mmol}$ ) in 1,4-dioxane (80 $\mathrm{mL}$ ) and the procedure $\boldsymbol{B}$ was performed. The residue was purified by chromatography on silica gel $\left(\mathrm{CH}_{2} \mathrm{Cl}_{2} /\right.$ Methanol $\left.98 / 2\right)$ to afford $0.29 \mathrm{~g}$ of pure compound MR29015 as a white solid (74\% yield). Mp: $193{ }^{\circ} \mathrm{C} .{ }^{1} \mathrm{H}$ $\operatorname{NMR}\left(\mathrm{CDCl}_{3}\right) \delta 8.92(\mathrm{~d}, J=1.9 \mathrm{~Hz}, 1 \mathrm{H}), 8.88(\mathrm{~d}, J=1.9 \mathrm{~Hz}, 1 \mathrm{H}), 8.82(\mathrm{~d}$, $J=1.9 \mathrm{~Hz}, 3 \mathrm{H}), 8.69(\mathrm{dd}, J=7.8,1.9 \mathrm{~Hz}, 1 \mathrm{H}), 8.68(\mathrm{~d}, J=1.9 \mathrm{~Hz}, 1 \mathrm{H})$, $7.96(\mathrm{~m}, 2 \mathrm{H}), 7.93(\mathrm{~d}, J=1.9 \mathrm{~Hz}, 2 \mathrm{H}), 7.85(\mathrm{~d}, J=1.9 \mathrm{~Hz}, 1 \mathrm{H}), 7.45(\mathrm{~m}$, $2 \mathrm{H}), 2.57(\mathrm{~s}, 3 \mathrm{H}), 2.56(\mathrm{~s}, 3 \mathrm{H}), 2.49(\mathrm{~s}, 3 \mathrm{H}) .{ }^{13} \mathrm{C} \mathrm{NMR}\left(\mathrm{CDCl}_{3}\right) \delta 154.9,154.7$, 154.6, 149.9, 149.4, 149.1, 148.2, 147.4, 147.3, 145.7, 139.3 (2C), 137.2, $136.5,135.9,135.0,134.8,134.3,133.0,132.6,131.5,131.1,131.0,123.8$ 123.1, 20.1, 20.0, 19.9. MS (ESI+): $m \mid z 430.71\left(\mathrm{M}+\mathrm{H}^{+}\right), 431.65\left(\mathrm{M}+2 \mathrm{H}^{+}\right)$. HRMS (ES): $m / z$ calcd for $\mathrm{C}_{28} \mathrm{H}_{23} \mathrm{~N}_{5}[\mathrm{M}+\mathrm{H}]^{+} 430.1953$, found 430.1961 .

\section{3-(4-Bromo-3-methylphenyl)pyridine 8}

To a reaction vessel in a nitrogen atmosphere containing 2-bromo-5iodotoluene $(1.0 \mathrm{~g}, 3.36 \mathrm{mmol}$ ) were added 3-pyridylboronic acid ( 1.3 equiv $0.52 \mathrm{~g}, 4.21 \mathrm{mmol}$ ), tetrakis(triphenylphosphine)palladium(0) $(0.19 \mathrm{~g}, 0.17$ $\mathrm{mmol}, 5 \% \mathrm{~mol})$ and aqueous $\mathrm{Na}_{2} \mathrm{CO}_{3}(0.89 \mathrm{~g}, 8.42 \mathrm{mmol}, 2.5$ equiv) in 1,4dioxane $(150 \mathrm{~mL})$ and procedure $\boldsymbol{A}$ was performed. After cooling down to room temperature, the mixture was filtered on Celite and the pad was washed with $\mathrm{CH}_{2} \mathrm{Cl}_{2}(150 \mathrm{~mL})$. The organic layers were collected, washed with brine, dried over anhydrous magnesium sulfate, filtered and concentrated under reduced pressure to give the crude product which was purified by chromatography on silica gel (c-hexane/ethyl acetate $9 / 1)$ to afford $0.71 \mathrm{~g}$ of pure compound 8 as a yellow oil ( $85 \%$ yield). ${ }^{1} \mathrm{H}$ NMR $\left(\mathrm{CDCl}_{3}\right) \delta 8.80(\mathrm{~d}, J=2.9,1 \mathrm{H}), 8.60(\mathrm{~d}, J=4.9,1 \mathrm{H}), 7.83(\mathrm{dt}, J=7.8,2.0$, $1 \mathrm{H}), 7.62(\mathrm{~d}, J=8.8,1 \mathrm{H}), 7.43(\mathrm{~d}, J=2.0,1 \mathrm{H}), 7.35(\mathrm{dd}, J=7.8,4.9,1 \mathrm{H})$, 7.25 (dd, $J=8.8,2.0,1 \mathrm{H}), 2.47(\mathrm{~s}, 3 \mathrm{H}) .{ }^{13} \mathrm{C}$ NMR $\left(\mathrm{CDCl}_{3}\right) \delta 148.7,148.1$, 138.7, 137.0, 135.7, 134.2, 133.0, 129.5, 126.0, 125.0, 123.6, 23.1. MS $(\mathrm{ESI}+)$ : $m \mid z 248.37\left(\mathrm{M}+\mathrm{H}^{+}\right), 250.39\left(\mathrm{M}^{+}+2\right), 251.40\left(\mathrm{M}^{+}+3\right)$.

\section{2-Methyl-4-(pyridin-3-yl)phenyl boronic acid 9}

To a slurry solution of $n$-BuLi $(4.03 \mathrm{~mL}, 10.07 \mathrm{mmol}, 1.3$ equiv) in anhydrous THF $(20 \mathrm{~mL})$, cooled to $-78^{\circ} \mathrm{C}$, was added a solution $3-(4-$ bromo-3-methylphenyl)pyridine $8(2.0 \mathrm{~g}, 8.06 \mathrm{mmol})$ in THF $(50 \mathrm{~mL})$. The mixture was allowed to react at this temperature for over $1 \mathrm{~h}$. A solution of triisopropylborate $(2.32 \mathrm{~mL}, 10.07 \mathrm{mmol}, 1.3$ equiv) was then added and left to react for $45 \mathrm{~min}$. The mixture was allowed to warm to room temperature and was quenched by slow addition of $1 \mathrm{M} \mathrm{NaOH}$ solution $(100 \mathrm{~mL})$. The resulting aqueous layer was collected and acidified to $\mathrm{pH}-$ 7 by dropwise addition of $3 \mathrm{~N} \mathrm{HCl}$ solution. The solution was extracted with ethyl acetate $(3 \times 100 \mathrm{~mL})$. The organic layers were collected, washed with brine, dried over anhydrous magnesium sulfate, filtered and concentrated under reduced pressure to give the crude product which was recrystallized from diethyl ether give $1.17 \mathrm{~g}$ of pure compound 9 as white solid (68\%) Mp: $184{ }^{\circ} \mathrm{C} .{ }^{1} \mathrm{H} \mathrm{NMR}\left(\mathrm{CDCl}_{3}\right) \delta 8.79(\mathrm{~d}, J=2.0,1 \mathrm{H}), 8.50(\mathrm{dd}, J=5.0,1.5$ $1 \mathrm{H}), 8.09(\mathrm{dt}, J=7.5,1.5,1 \mathrm{H}), 7.51(\mathrm{dd}, J=8.0,5.0,1 \mathrm{H}), 7.49(\mathrm{~s}, 1 \mathrm{H})$, $7.46(\mathrm{~d}, J=8.0,1 \mathrm{H}), 7.40(\mathrm{~d}, J=8.0,1 \mathrm{H}), 2.42(\mathrm{~s}, 3 \mathrm{H}) .{ }^{13} \mathrm{C} \mathrm{NMR}\left(\mathrm{CDCl}_{3}\right)$ $\delta 148.7,148.3,142.3,138.8,138.7,136.5,135.4,133.3,128.8,125.5$, 124.6, 22.1. $\mathrm{MS}(\mathrm{ESI}+): m \mid z 214.45\left(\mathrm{M}+\mathrm{H}^{+}\right), 215.48\left(\mathrm{M}^{+}+2 \mathrm{H}^{+}\right)$.

\section{5-Bromo-2-(pyridin-3-yl)benzaldehyde 10}

To a reaction vessel in a nitrogen atmosphere containing 2,5dibromobenzaldehyde $(2.0 \mathrm{~g}, 7.58 \mathrm{mmol})$ were added 3-pyridylboronic

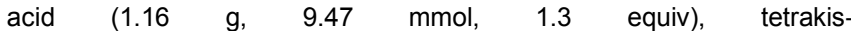
(triphenylphosphine)palladium $(0)(0.44 \mathrm{~g}, 0.38 \mathrm{mmol}, 5 \% \mathrm{~mol})$ and aqueous $\mathrm{Na}_{2} \mathrm{CO}_{3}(2.0 \mathrm{~g}, 18.94 \mathrm{mmol}, 2.5$ equiv) in 1,4-dioxane $(100 \mathrm{~mL})$ following procedure $\boldsymbol{A}$. After cooling down to room temperature, the mixture was filtered on Celite and the pad was washed with $\mathrm{CH}_{2} \mathrm{Cl}_{2}(300$ $\mathrm{mL}$ ). The organic layers were collected, washed with brine, dried over anhydrous magnesium sulfate, filtered and concentrated under reduced pressure to give the crude product which was purified by chromatography on silica gel (c-hexane/ethyl acetate 9/1) to afford $1.6 \mathrm{~g}$ of pure compound 10 as a white solid $\left(80 \%\right.$ yield). $\mathrm{Mp}: 140{ }^{\circ} \mathrm{C}$. ${ }^{1} \mathrm{H}$ NMR $\left(\mathrm{CDCl}_{3}\right) \delta 9.90$ (s $1 \mathrm{H}), 8.72(\mathrm{dd}, J=4.9,2.0,1 \mathrm{H}), 8.65(\mathrm{~s}, 1 \mathrm{H}), 8.19(\mathrm{~d}, J=2.0,1 \mathrm{H}), 7.81$ (dd, $J=7.8,2.0,1 \mathrm{H}), 7.70(\mathrm{dd}, J=7.8,2.0,1 \mathrm{H}), 7.44(\mathrm{dd}, J=7.8,4.9,1 \mathrm{H})$ $7.32(\mathrm{~d}, J=7.8,1 \mathrm{H}) .{ }^{13} \mathrm{C}$ NMR $\left(\mathrm{CDCl}_{3}\right) \delta 189.7,149.9(2 \mathrm{C}), 149.7,140.4$, 137.0, 136.7, 134.9, 132.5, 131.2, 123.2, 123.1. MS (ESI+): $262.39(\mathrm{M}+$ $\left.\mathrm{H}^{+}\right)$, 264.40. $\left(\mathrm{M}^{+}+2\right)$

\section{2-(Pyridin-3-yl)-5-(2-methyl-4-pyridin-3-ylphenyl)benzaldehyde 11}

To a reaction vessel in a nitrogen atmosphere containing 5-bromo-2(pyridin-3-yl)benzaldehyde 10 (0.500 g, $1.91 \mathrm{mmol}$ ) were added 2-methyl4-(pyridin-3-yl)phenylboronic acid $9(0.51 \mathrm{~g}, 2.38 \mathrm{mmol}, 1.3$ equiv), tetrakis(triphenylphosphine)palladium $(0)(0.11 \mathrm{~g}, 0.10 \mathrm{mmol}, 5 \% \mathrm{~mol})$ and aqueous $\mathrm{K}_{3} \mathrm{PO}_{4}(1.01 \mathrm{~g}, 4.77 \mathrm{mmol}, 2.5$ equiv) in dimethoxyethane (80 $\mathrm{mL}$ ). The mixture was stirred at reflux $18 \mathrm{~h}$ following by TLC the consumption of starting material. After cooling down to room temperature, the mixture was filtered on Celite and the pad was washed with $\mathrm{CH}_{2} \mathrm{Cl}_{2}$ $(100 \mathrm{~mL})$. The organic layers were collected, washed with brine, dried over anhydrous magnesium sulfate, filtered and concentrated under reduced pressure to give the crude product which was purified by chromatography on silica gel (c-hexane/ethyl acetate 1/1) to afford $0.62 \mathrm{~g}$ of pure compound 11 as a white solid $\left(93 \%\right.$ yield). Mp: $162{ }^{\circ} \mathrm{C} .{ }^{1} \mathrm{H}$ NMR $\left(\mathrm{CDCl}_{3}\right) \delta 10.06$ (s, $1 \mathrm{H}), 8.75(\mathrm{~s}, 1 \mathrm{H}), 8.73(\mathrm{~s}, 1 \mathrm{H}), 8.63(\mathrm{~d}, J=4.6,2 \mathrm{H}), 8.08(\mathrm{~d}, J=2.0,1 \mathrm{H})$, $7.93(\mathrm{dt}, J=8.0,1.7,1 \mathrm{H}), 7.79(\mathrm{dd}, J=8.0,1.9,1 \mathrm{H}), 7.71$ (dd, $J=7.8,2.0$, $1 \mathrm{H}), 7.54-7.48(\mathrm{~m}, 3 \mathrm{H}), 7.51-7.45(\mathrm{~m}, 1 \mathrm{H}), 7.42-7.38(\mathrm{~m}, 2 \mathrm{H}), 2.42(\mathrm{~s}$, 3H). ${ }^{13} \mathrm{C}$ NMR $\left(\mathrm{CDCl}_{3}\right) \delta 191.2,150.1,149.4,148.6,148.3,141.9,140.4$, 139.7, 137.5, 137.2, 136.1, 136.0, 134.5, 134.3, 133.6, 133.4, 131.0, 130.5, 129.3, 129.0, 124.8, 123.6, 123.2, 20.6. MS (ESI+): $m l z 351.50\left(\mathrm{M}+\mathrm{H}^{+}\right)$, $352.44\left(\mathrm{M}+2 \mathrm{H}^{+}\right)$.

\section{2-(Pyridin-3-yl)-5-(2-methyl-4-pyridin-3-ylphenyl)-(E)styrylphenyl (MR30821)}

To a stirred solution of diethyl benzylphosphonate $(0.07 \mathrm{~g}, 0.28 \mathrm{mmol}, 1.0$ equiv) in THF $(20 \mathrm{~mL})$ under nitrogen flow was added $\mathrm{KOH}(0.03 \mathrm{~g}, 0.57$ $\mathrm{mmol}, 2.0$ equiv). After $30 \mathrm{~min}$ of stirring, 2-(pyridin-3-yl)-5-(2-methyl-4pyridin-3-ylphenyl)benzaldehyde $11(0.10 \mathrm{~g}, 0.28 \mathrm{mmol})$ was added. The mixture was stirred at room temperature for $1 \mathrm{~h}$ and then refluxed $5 \mathrm{~h}$ until the starting material was consumed (TLC). The mixture was cooled to room temperature, quenched with water and extracted with ethyl acetate $(3 \times 50 \mathrm{~mL})$. The organic layers were collected, washed with brine, dried over anhydrous magnesium sulfate, filtered and concentrated under reduced pressure to give the crude compound that was purified by column chromatography (c-hexane/ethyl acetate 1/1) affording $0.10 \mathrm{~g}$ of pure compound MR30821 as a yellow solid (85\%). Mp: $139^{\circ} \mathrm{C} .{ }^{1} \mathrm{H} \mathrm{NMR}\left(\mathrm{CDCl}_{3}\right)$ $\delta 8.94(\mathrm{~s}, 1 \mathrm{H}), 8.77(\mathrm{~s}, 1 \mathrm{H}), 8.66(\mathrm{~s}, 1 \mathrm{H}), 8.61(\mathrm{~s}, 1 \mathrm{H}), 7.93(\mathrm{~d}, J=8.0,1 \mathrm{H})$, $7.79(\mathrm{~s}, 1 \mathrm{H}), 7.55-7.23(\mathrm{~m}, 13 \mathrm{H}), 7.12(\mathrm{~s}, 2 \mathrm{H}), 2.47(\mathrm{~s}, 3 \mathrm{H}) .{ }^{13} \mathrm{C}$ NMR $\left(\mathrm{CDCl}_{3}\right) \delta 150.2,148.3(2 \mathrm{C}), 148.1,141.2,141.0,137.0,136.9,136.1(2 \mathrm{C})$, 135.8, 135.5, 134.1 (2C), 130.7, 130.4, 130.1, 129.1, 128.6 (2C), 128.4, $127.7,126.8,126.5(2 \mathrm{C}), 126.4,124.5,123.5,122.9,20.6$. MS (ESI+): $m \mid z$ 
$425.56\left(\mathrm{M}+\mathrm{H}^{+}\right), 426.63\left(\mathrm{M}+2 \mathrm{H}^{+}\right)$. HRMS (ES): $\mathrm{m} / z$ calcd for $\mathrm{C}_{31} \mathrm{H}_{24} \mathrm{~N}_{2}$ $[\mathrm{M}+\mathrm{H}]^{+} 425.2018$, found 425.2018 .

\section{5-Bromo-2-(3-pyridyl)pyridine 12}

To a reaction vessel in a nitrogen atmosphere containing 2,5dibromopyridine $(5.85 \mathrm{~g}, 24.6 \mathrm{mmol})$ were added 3-pyridylboronic acid $(3.79 \mathrm{~g}, 30.75 \mathrm{mmol}, 1.3$ equiv), tetrakis(triphenylphosphine)palladium(0) $(1.42 \mathrm{~g}, 1.23 \mathrm{mmol}, 5 \% \mathrm{~mol})$ and aqueous $\mathrm{Na}_{2} \mathrm{CO}_{3}(6.54 \mathrm{~g}, 61.50 \mathrm{mmol}$, 2.5 equiv) in 1,4-dioxane ( $300 \mathrm{~mL}$ ) and procedure $\boldsymbol{A}$ was performed. The crude product was purified by chomatography on silica gel ( $c$-hexane/ethyl acetate $4 / 1)$ to afford $3.70 \mathrm{~g}$ of pure compound 12 as a white solid $(64 \%$ yield). Mp: $78{ }^{\circ} \mathrm{C} .{ }^{1} \mathrm{H} \mathrm{NMR}\left(\mathrm{CDCl}_{3}\right) \delta 9.16(\mathrm{dd}, J=2.3,0.8 \mathrm{~Hz}, 1 \mathrm{H}), 8.76$ (dd, $J=2.4,0.6 \mathrm{~Hz}, 1 \mathrm{H}$ ), 8.66 (dd, $J=4.8,1.7 \mathrm{~Hz}, 1 \mathrm{H}$ ), 8.29 (ddd, $J=8.0$, 2.3, $1.7 \mathrm{~Hz}, 1 \mathrm{H}), 7.91(\mathrm{dd}, J=8.4,2.4 \mathrm{~Hz}, 1 \mathrm{H}), 7.65(\mathrm{dd}, J=8.4,0.7 \mathrm{~Hz}$ $1 \mathrm{H}), 7.40$ (ddd, $J=8.0,4.8,0.8 \mathrm{~Hz}, 1 \mathrm{H}) .{ }^{13} \mathrm{C} \mathrm{NMR}\left(\mathrm{CDCl}_{3}\right) \delta 153.30,151.24$ $150.35,148.11,139.64,134.23,133.84,123.72,121.66,120.28,77.41$, 77.30, 77.10, 76.78. MS (ESI+): $m \mid z 235.42\left(\mathrm{M}+\mathrm{H}^{+}\right), 237.37\left(\mathrm{M}^{+}+2\right)$.

\section{2-(3-Pyridyl)-5-[6-(3-pyridyl)-3-pyridyl]pyridine (MR33718)}

To a reaction vessel in a nitrogen atmosphere containing 5-bromo-2-(3pyridyl)pyridine $12(0.25 \mathrm{~g}, 1.06 \mathrm{mmol})$ were added bispinacolato diboron ( $0.14 \mathrm{~g}, 0.55 \mathrm{mmol}, 0.52$ equiv), $\mathrm{PdCl}_{2}$ (dppf) $(0.09 \mathrm{~g}, 0.11 \mathrm{mmol}, 10 \% \mathrm{~mol})$ and aqueous $\mathrm{KOAc}(0.26 \mathrm{~g}, 2.65 \mathrm{mmol}, 2.5$ equiv) in 1,4-dioxane $(50 \mathrm{~mL})$. The mixture was refluxed $3 \mathrm{~h}$, until the starting material was consumed (TLC), cooled to room temperature, quenched with water and extracted with $\mathrm{CH}_{2} \mathrm{Cl}_{2}(3 \times 50 \mathrm{~mL})$. The organic layers were collected, washed with brine, dried over anhydrous magnesium sulfate, filtered and concentrated under reduced pressure to give the crude compound that was purified by column chromatography on silica gel $\left(\mathrm{CH}_{2} \mathrm{Cl}_{2} /\right.$ Methanol $\left.98 / 2\right)$ to afford 0.09 $\mathrm{g}$ of pure compound MR33718 as a brown solid (56\% yield). Mp: $240{ }^{\circ} \mathrm{C}$. ${ }^{1} \mathrm{H} \mathrm{NMR}\left(\mathrm{CDCl}_{3}\right) \delta 9.28(\mathrm{~d}, J=1.7 \mathrm{~Hz}, 2 \mathrm{H}), 9.03(\mathrm{~d}, J=1.8 \mathrm{~Hz}, 2 \mathrm{H}), 8.70$ (dd, $J=4.7,1.4 \mathrm{~Hz}, 2 \mathrm{H}$ ), 8.41 (dt, $J=8.0,1.9 \mathrm{~Hz}, 2 \mathrm{H}$ ), 8.07 (dd, $J=8.2$, $2.4 \mathrm{~Hz}, 2 \mathrm{H}), 7.92(\mathrm{~d}, J=8.2 \mathrm{~Hz}, 2 \mathrm{H}), 7.46(\mathrm{dd}, J=7.9,4.8 \mathrm{~Hz}, 2 \mathrm{H}) .{ }^{13} \mathrm{C}$ $\operatorname{NMR}\left(\mathrm{CDCl}_{3}\right) \delta 154.51,150.28,148.27,135.21,134.30,134.16,132.07$, 123.72, 120.64. MS (ESI+): $m \mid z 311.54\left(\mathrm{M}+\mathrm{H}^{+}\right), 312.48\left(\mathrm{M}+2 \mathrm{H}^{+}\right)$. HRMS (ES): $m / z$ calcd for $\mathrm{C}_{20} \mathrm{H}_{14} \mathrm{~N}_{4}[\mathrm{M}+\mathrm{H}]^{+} 311.1297$, found 311.1301.

\section{Physico-chemical studies}

\section{Calculated physico-chemical properties}

Values of molecular weight, pKa, calc logP, the number of hydrogen-bond acceptors, of rotatable bonds, of aromatic rings in scaffold, of lateral alkyl substituents, and the polar surface area were calculated for the studied molecules using standard tools of the ChemAxon Package (Marvin 16.1.4.0, 2016, ChemAxon (http://www.chemaxon.com/). Calc logP values were also predicted using Discovery Studio, ${ }^{[55]}$ Schrödinger, ${ }^{[56]}$ and Molinspiration (http://www.molinspiration.com/cgi-bin/properties/).

\section{Thermodynamic solubility determination}

Thermodynamic solubility at $\mathrm{pH} 7.4$ of compounds was determined according to the classical shake-flask method (Organisation for Economic Cooperation and Development guideline $n^{\circ} 105$ ) and adapted from a miniaturized procedure described elsewhere [57]. Phosphate Buffer solutions ( $\mathrm{pH} 7.4,10 \mu \mathrm{M}$, ionic strength $150 \mathrm{mM}$ ) were prepared from $\mathrm{Na}_{2} \mathrm{HPO}_{4}, \mathrm{KH}_{2} \mathrm{PO}_{4}$ and $\mathrm{KCl}$ (Sigma Aldrich, Saint Quentin Fallavier, France); $10 \mu \mathrm{L}$ of $50 \mathrm{mM}$ stock solution was added to $1.5 \mathrm{~mL}$ microtubes (3 replicates) containing $990 \mathrm{~mL}$ buffer $(n=4)$. Tubes were briefly sonicated and shacked by inversion during $24 \mathrm{~h}$ at room temperature. Then, microtubes were centrifuged at $12,225 \times \mathrm{g}$ for $5 \mathrm{~min}$; $100 \mu \mathrm{L}$ supernatant was mixed with $100 \mu \mathrm{L}$ acetonitrile in a Greiner UV microplate. Standard solutions were prepared extemporaneously diluting $50 \mathrm{mM}$ DMSO stock solutions at 0,10 and $25 \mathrm{mM} ; 5 \mu \mathrm{L}$ each working solution was diluted with $995 \mu \mathrm{L}$ buffer and $100 \mu \mathrm{L}$ was then mixed in microplate with $100 \mu \mathrm{L}$ acetonitrile to keep unchanged the final proportions of each solvent in standard solutions and samples. Determination of solubility at $\mathrm{pH} 7.4$ was made with a Synergy 2 (Biotek, Colmar, France) microplate reader in spectrophotometric mode ( 230 to $450 \mathrm{~nm}$ ) from the specific $\lambda_{\max }$ of each compound. The calibration curve obtained from the three standard solutions of tested compounds at 0,50 , and $100 \mu \mathrm{M}$ in a $50: 50$ ( $\mathrm{vol} / \mathrm{vol})$ mixture of buffer with acetonitrinile/DMSO (99:1; vol/vol). Calibration curves were linear with $R^{2}>0.99$.

\section{Permeability evaluation}

The Pampa-GIT experiments were conducted using the Pampa Explorer Kit (Pion Inc) according to manufacturer's protocol. Briefly, each stock compound solution (20 mM in DMSO) was diluted in Prisma HT buffer $\mathrm{pH}$ 7.4 (plON) to $100 \mu \mathrm{M} .200 \mu \mathrm{L}$ of these solutions $(n=4)$ were added to the donor plate (P/N 110243). $5 \mu \mathrm{L}$ of the GIT-0 Lipid (P/N 110669) was used to coat the membrane filter of the acceptor plate (P/N 110243). $200 \mu \mathrm{L}$ of the Acceptor Sink Buffer (P/N 110139) was added to each well of the acceptor plate. The sandwich was incubated at room temperature for $4 \mathrm{~h}$ without stirring. After incubation, the UV-visible spectra were measured with the microplate reader (Tecan infinite M200) and for each compound, the -logPe and Pe were calculated by the PAMPA Explorer software v. 3.7 (pION). As recommended by the manufacturer, ketoprofen and antipyrin were used as low $(\mathrm{Pe}=8 \mathrm{~nm} / \mathrm{s}$ at $\mathrm{pH} 7.4)$ and moderately $(\mathrm{Pe}=16 \mathrm{~nm} / \mathrm{s}$ at $\mathrm{pH}$ 7.4) permeable references, respectively.

\section{Experimental chrom logP determination}

Chrom logP estimation was carried out using an isocratic liquid chromatography method for basic compounds derived from method described by Henchoz. ${ }^{[25]}$ All experiments were performed on a UHPLC Agilent 1290 Infinity system (Agilent Technologies, Santa Clara, California, USA) equipped with a PDA detector 1260 operating at 220, 240, 254, 290 and $350 \mathrm{~nm}$ for all compounds. The chromatographic system was controlled by Open LAB CDS LC Chemstation ${ }^{\circledR}$ software (revision C01.05). Retention time measurement was performed at $27^{\circ} \mathrm{C}$, with a flow rate 0.6 $\mathrm{mL} . \mathrm{min}^{-1}$, and by using an Acquity BEH Shield RP18 column (1.7 $\mu \mathrm{m}, 2.1$ $x 50 \mathrm{~mm}$ ) from Waters (Milford, MA, USA). Mobile phase was composed by various percentage of methanol as organic modifier (35-85\%) and an aqueous basic buffer (triethylammonium acetate solution at $\mathrm{pH} 11.5$ ) adjusted by sodium hydroxide addition) in order to keep calibration and newly synthesized compounds in their neutral form.

Briefly, chrom $\log \mathrm{P}$ was estimated by plotting the known $\log \mathrm{P}^{[22]}$ values of 9 standard compounds with their $\log \mathrm{k}_{49 \%}$, which is the retention factor at $49 \%$ methanol in the mobile phase. Calculation of log $k_{49} \%$ values was performed from retention time ( $\left.t_{R}\right)$ measurement at three different mobile phase compositions. Standard compounds were cimetidine, labetalol, pindolol, papaverine, quinine, tetracaine, promethazine, chlorpromazine, amiodarone which present a large range of $\log P$ values from 0.48 to 7.8 . Each compound was injected $(1 \mu \mathrm{L})$ once with each mobile phase composition and $t_{R}$ determined from the apex of the peak. Log $k_{49} \%$ values were obtained by extrapolation to $49 \%$ organic modifier using linear relationships between the three log $\mathrm{k}$ values and methanol percentage ( $r^{2}>0.99$ for all compounds).

Then calibration curve was built with experimentally determined $\log \mathrm{P}$ values of standards compounds obtained from literature ${ }^{[22]} v s$ their log $\mathrm{k}_{49 \%}$. Linear relationship between $\log \mathrm{P}$ and calculated $\log \mathrm{k}_{49 \%}$ was expressed by the following equation:

$\log \mathrm{k}_{49 \%}=0.5226 \times \log \mathrm{P}-0.7058$, with $\mathrm{r}^{2}=0.978$ and $\mathrm{F}=444$ [2]

As described by Henchoz ${ }^{[25]}$, the use of the Acquity BEH shield column with a $\log \mathrm{k}_{49 \%}$ provides the best correlation results with experimental $\log \mathrm{P}$ values obtained with basic compounds.

Large Unilamellar Vesicles (LUVs) preparation and characterization Two formulations of LUVs, with or without cholesterol (chol), have been prepared according to the thin film hydration method and resized by extrusion. ${ }^{[58]}$ Briefly, phosphatidylcholine (PC from soybean, Lipoid S 100 was a gift of Lipoid $\mathrm{GmbH}$, Ludwigshafen, Germany) and 1,2-dioleoyl-snglycero-3-phospho-rac-1-glycerol sodium salt (DOPG-Na, Lipoid PG 18:1 kindly provided by Lipoid $\mathrm{GmbH}$, Ludwigshafen, Germany) have been mixed in a weight/weight $(\mathrm{w} / \mathrm{w})$ ratio of $4: 1$ (PC:DOPG) for the first formulation of LUVs, with the addition of chol (Sigma-Aldrich, SaintQuentin Fallavier, France), in a w/w ratio of 4:1:1 (PC:DOPG:chol), for the second one. Then, lipids mix has been dissolved in an adequate amount of chloroform and after evaporation of organic solvent under a stream of 
nitrogen, the dried film was kept overnight in a vacuum desiccator to remove any residual trace of solvent. The resultant lipid film has been hydrated with a buffer A (50 mM HEPES, $10 \mathrm{mM} \mathrm{NaCl}, 1 \mathrm{mM}$ EDTA, pH 7.4) and the mixture mixed by vortexing and then stirred for 1 hour at room temperature.

The fluorescence probes were directly dissolved in buffer B $(50 \mathrm{mM}$ HEPES, $107 \mathrm{mM} \mathrm{NaCl}, 1 \mathrm{mM}$ EDTA, pH 7.4) for carboxyfluorescein (CF, $11.6 \mathrm{mg} / \mathrm{mL}$ ) or during the hydratation phase for 1,6-diphenyl-1,3,5hexatriene (DPH, $11.6 \mathrm{mg} / \mathrm{mL}$ ) and 1-(4-trimethylammonium)-6-phenyl1,3,5-hexatriene (TMA-DPH, $11.6 \mathrm{mg} / \mathrm{mL}$ ) in DMSO.

Lipid mixtures have been then extruded 13 times through polycarbonate filters with a pore diameter of $100 \mathrm{~nm}$ and the obtained LUVs have been separated from possible unincorporated material by passage through a Sepharose CL-4B loaded column, using buffer B (50 mM HEPES, $107 \mathrm{mM}$ $\mathrm{NaCl}, \mathrm{pH} 7.4$ ) as eluent. The LUVs size and charge have been assessed by Dynamic Light Scattering (DLS, NanoZS, Malvern Instruments, Worcestershire, UK) after 1/100 dilution in buffer B. Granulometric properties and $\zeta$-potential values of various formulations are presented in Table S1 (see supporting information).

The entrapment of $\mathrm{CF}$ has been verified by dequenching of fluorescence after the addition of $10 \%(\mathrm{v} / \mathrm{v})$ Triton X-100 measured with a Synergy 2 microplate reader (Biotek, Colmar, France) equipped with the appropriate filters $(\lambda e x=485 / 20 \mathrm{~nm}$ and $\lambda e m=528 / 20 \mathrm{~nm})$. All the LUVs used in these experiments have been stored at $4^{\circ} \mathrm{C}$ and were stable for at least one week.

\section{Emission fluorescence spectra measurements}

Emission fluorescence spectra were recorded in the range $\lambda e m=[350-$ $600 \mathrm{~nm}$ ] with a Tecan infinite M200 microplate reader. An excitation wavelength of $285 \mathrm{~nm}$ was chosen to record emission fluorescence spectra of the various compounds first solubilized in DMSO, and then diluted in buffer $B$ ( 50 mM HEPES, $107 \mathrm{mM} \mathrm{NaCl}, 1 \mathrm{mM}$ EDTA, pH 7.4) to reach a final concentration of 10 or $25 \mu \mathrm{M}$ in a final volume of $200 \mu \mathrm{L}$. To study interactions of molecules with biomimetic membranes, in parallel, by keeping unchanged the final volume, spectra were also recorded in additional presence of $2 \mu \mathrm{L}$ of LUVs or chol-LUVs previously prepared.

\section{Carboxyfluorescein efflux}

CF release assay has been performed in a final volume of $200 \mu \mathrm{L}$, using 2 $\mu \mathrm{L}$ of the CF-loaded LUVs stock solution in buffer B. Compounds to test, solubilized in DMSO, have been then added to the solution to reach a final concentration of 10 or $25 \mu \mathrm{M}$. The fluorescence has been recorded immediately (to) and after $4 \mathrm{~h}$, using a Synergy 2 microplate reader controlled by Gen 5 software (Biotek, Colmar, France) microplate reader at $\lambda$ ex $485 / 20 \mathrm{~nm}$ and $\lambda e m 528 / 20 \mathrm{~nm}$, at room temperature. The fluorescence intensities at each time point have been normalized to the signal when CF-loaded LUVs have been disintegrated by the addition of $100 \mu \mathrm{L}$ of a $10 \%(\mathrm{~V} / \mathrm{V})$ Triton $\mathrm{X}-100$ solution. The percentage of CF leakage has been calculated using the following equation

CF release $(\%)=\frac{\mathrm{I}_{\mathrm{t}}-\mathrm{I}_{0}}{\mathrm{I}_{\mathrm{T}}-\mathrm{I}_{0}} \times 100$

where $I_{t}$ corresponds to the fluorescence intensity after $4 \mathrm{~h}$ of incubation of LUVs with the studied compound, $\mathrm{I}_{0}$ is the initial fluorescence intensity of the negative control, $\mathrm{I}_{\mathrm{T}}$ is the fluorescence intensity after CF-loaded LUVs disruption by the addition of $10 \%$ Triton X-100 solution. Each experiment has been performed in triplicate.

\section{$D P H$ and TMA-DPH fluorescence quenching measurements}

With the DPH-loaded or TMA-DPH-loaded LUVs samples prepared as described above, fluorescence intensity was measured at room temperature, at time 0 and 4 hours, using a Synergy 2 Biotek microplate reader (Biotek, Colmar, France) set at $360 \mathrm{~nm}$ for excitation and $460 \mathrm{~nm}$ for emission, with a $40 \mathrm{~nm}$ bandwidth. Assays were performed in a final volume of $200 \mu \mathrm{L}$ in black microplates, using $2 \mu \mathrm{L}$ of the probe-loaded LUVs stock solution in buffer B and compounds to test, solubilized in DMSO, and added to the samples to reach a final concentration of 10 or $25 \mu \mathrm{M}$. Assays were performed in duplicate.

Fluorescence quenching was calculated as follows:

$\mathrm{I}_{0} / \mathrm{I}=\frac{\mathrm{I}_{\text {probe-loaded LUV }}-\mathrm{I}_{\text {unloaded LUV }}}{\mathrm{I}_{\text {probe-loaded LuV+oligopyridine }} \mathrm{I}_{\text {unloaded LUV }+ \text { oligopyridine }}}$ where $I_{0}$ and $I$ are the corrected fluorescence intensity of the probes (DPH or TMA-DPH) in the absence and in presence of the drug, respectively. Rifampicin ( 10 and $25 \mu \mathrm{M}$ ), known to be able to penetrate into membranes, was used as reference. ${ }^{[52]}$

\section{Ellipsometry and Surface Pressure Measurements}

Experiments were performed with a computer-controlled and userprogrammable Langmuir Teflon ${ }^{\circledR}$-coated trough (type 601BAM) equipped with two movable barriers and of total surface $90 \mathrm{~cm}^{2}$ (Nima Technology Ltd., England). Before starting the experiments, the trough was cleaned successively with ultrapure water (Nanopure-UV), ethanol, and finally ultrapure water. The trough was filled with HEPES-buffer (50 mM HEPES, $107 \mathrm{mM} \mathrm{NaCl}, \mathrm{pH}$ 7.4).

For lipid free interface or air/lipid interface experiments, the MR29072 solution was injected in the sub-phase using a Hamilton syringe to obtain the final concentration of $10 \mu \mathrm{M}$ or $25 \mu \mathrm{M}$.

To test the lipid/oligopyridine interactions, the lipid monolayers were performed on the air/buffer interface by spreading the lipid solution with a high precision Hamilton microsyringe to obtain an initial surface pressure around $30 \mathrm{mN} / \mathrm{m}$. This surface pressure value was selected because it is known as similar to the in vivo membrane pressure. ${ }^{[59]}$ After $10 \mathrm{~min}$ necessary to allow solvent evaporation, the oligopyridine solution was injected in the subphase. The lipid solution concentration was $1 \mathrm{mg} / \mathrm{mL}$ and contained a binary mixture of DOPC and DOPG (Dioleoylphosphatidylcholine DOPC, Dioleoylphosphatidylglycerol DOPG all $>99 \%$ purity; Aventi Polar lipids, Alabaster, AL) solubilized on chloroform/methanol solvent (2/1).

The ellipsometric angle $\left(\Delta,{ }^{\circ}\right)$ and the surface pressure $(\Pi, \mathrm{mN} / \mathrm{m})$ were recorded simultaneously during the kinetic absorption. Ellipsometric measurements were carried out with a home-made automated

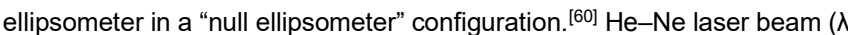
$=632.8 \mathrm{~nm}$, Melles Griot, France) was polarised with a Glan-Thompson polarizer and was reflected on the surface of the trough with an incidence angle of $52.12^{\circ}$. After reflection on the liquid surface, the laser light passed through a $\lambda / 4$ retardation plate, a Glan-Thompson analyser and a photomultiplier. The analyser angle, multiplied by two, yielded the value of the ellipsometric angle $(\Delta)$ i.e., the phase difference between parallel and perpendicular polarisation of the reflected light. The laser beam probed a surface of $1 \mathrm{~mm}^{2}$ and a depth in the order of $1 \mu \mathrm{m}$ and gives insight on the amount of interfacial matter. Indeed, this ellipsometric angle is dependent on two parameters: the reflective index and the thickness of the interface. Values of $\Delta$ were recorded every $4 \mathrm{~s}$ with a precision of $\pm 0.5^{\circ}$.

The surface pressure was measured following a Wilhelmy method using a filter paper as plate (Whatman, Velizy-Villacoublay, France) connected to a microelectronic feedback system (Nima PS4, Manchester, England). The surface pressure $(\pi)$ was recorded every $4 \mathrm{~s}$ with a precision of \pm 0.2 $\mathrm{mN} / \mathrm{m}$ until the equilibrium surface pressure. The surface pressure gives insight on the lateral interaction between the interfacial film molecules. ${ }^{[61,62]}$

\section{Atomic Force Microscopy (AFM) observations}

At the end of the kinetics (i.e. surface pressure and ellipsometric angle stable), a Langmuir-Blodgett (LB) transfer was performed onto freshly cleaved mica plates at constant surface pressure (the final one) by vertically raising $(1 \mathrm{~mm} / \mathrm{min})$ the mica plate through the air/liquid interface to obtain a sample of the interfacial monolayer. AFM imaging of LB films was performed in contact mode using a Multimode AFM (Nano-Bruker, Palaiseau, France) under ambient conditions with scanning areas $40 \mu \mathrm{m}$ $x 40 \mu \mathrm{m}$. Topographic images were acquired using silicon nitride tips on integral cantilevers with a nominal spring constant of $60 \mathrm{mN} / \mathrm{m}$ (Bruker, CA, USA). The forces were controlled and minimized along the imaging process. Three different areas were imaged for each sample to assure that the images here shown are representative for the whole sample. 


\section{Acknowledgements}

We are grateful for funding support from the "Ligue Contre le Cancer" (National and Calvados committees). Dr Domenico lacopetta was recipient of grant from Commissione Europea, Fondo Sociale Europeo (FSE 2007/2013-PROGRAMMA ARUE) and Regione Calabria. This work was also financially supported by the Region Normandie and the European Union via the European Regional Development Fund (FEDER). Lipoid S100 and Lipoid PG18:1 were kindly provided thanks to JeanGuillaume Giraudon (Lipoid $\mathrm{GmbH}$ ). The authors want to thank Siham Hedir, and Dr Laurent Poulain (Normandie Univ, UniCaen, Inserm U1086 Anticipe, Axe BioTICLA, Caen, France) for helpful discussions. We acknowledge also Peggy Suzanne (Chemical library, CERMN and SF4206 Icore, Normandie Univ, UNICAEN) for her helpful technical support.

Keywords: Analytical methods $\cdot$ medicinal chemistry $\bullet$ membrane models $\cdot$ oligopyridines $\cdot$ structure-properties relationships.

\section{Abbreviations used:}

AFM, atomic force microscopy; Calc logP, calculated logP ; CF, carboxyfluorescein; chol, cholesterol; chrom $\log \mathrm{P}, \quad \log \mathrm{P}$ determined by chromatographic method; DLS, diffusion light scattering; DOPC, dioleoylphosphatidylcholine; DOPG, 1,2dioleoyl-sn-glycero-3-phospho-rac-1-glycerol; DPH, 1,6-diphenyl1,3,5-hexatriene; HBA, hydrogen-bond acceptors; HBD, hydrogen-bond donors; HCA, hierarchical cluster analysis; LB, Langmuir-Blodgett; LUVs, large unilamellar vesicles; Mp, melting point; MW, molecular weight; ND, not determined; Pe, effective permeation rate; $\mathrm{PC}$, phosphatidylcholine; PSA, polar surface area; PPIs, protein-protein interactions; RO5, Lipinski's rules of 5; TMA-DPH, 1-(4-trimethylammonium)-6-phenyl-1,3,5-hexatriene.

\section{References:}

[1] R. Beroukhim, C. H. Mermel, D. Porter, G. Wei, S. Raychaudhuri, J. Donovan, J. Barretina, J. S. Boehm, J. Dobson, M. Urashima, et al., Nature 2010, 463, 899-905.

[2] A. Frenzel, F. Grespi, W. Chmelewskij, A. Villunger, Apoptosis 2009, 14, 584-596.

[3] E. Brotin, M. Meryet-Figuière, K. Simonin, R. E. Duval, M. Villedieu, J. Leroy-Dudal, E. Saison-Behmoaras, P. Gauduchon, C. Denoyelle, L. Poulain, Int. J. Cancer 2010, 126, 885-895.

[4] C. Gloaguen, A. S. Voisin-Chiret, J. Sopkova-de Oliveira Santos, J. Fogha, F. Gautier, M. De Giorgi, G. Burzicki, S. Perato, C. PétignyLechartier, K. Simonin-Le Jeune, et al., J. Med. Chem. 2015, 58, 16441668.

[5] C. A. Lipinski, F. Lombardo, B. W. Dominy, P. J. Feeney, Adv. Drug Deliv. Rev. 1997, 23, 3-25.

[6] C. A. Lipinski, F. Lombardo, B. W. Dominy, P. J. Feeney, Adv. Drug Deliv. Rev. 2001, 46, 3-26.

[7] G. L. Amidon, H. Lennernäs, V. P. Shah, J. R. Crison, Pharm. Res. 1995 12, 413-420.

[8] A. Bouillon, A. S. Voisin, A. Robic, J.-C. Lancelot, V. Collot, S. Rault, J. Org. Chem. 2003, 68, 10178-10180.

[9] A. S. Voisin-Chiret, A. Bouillon, G. Burzicki, M. Célant, R. Legay, H. ElKashef, S. Rault, Tetrahedron 2009, 65, 607-612.

[10] A. S. Voisin-Chiret, S. Rault, Pure Appl. Chem. 2012, 84, 2467-2478.
[11] G. Burzicki, A. S. Voisin-Chiret, J. S. Oliveira Santos, S. Rault, Tetrahedron 2009, 65, 5413-5417.

[12] G. Burzicki, A. S. Voisin-Chiret, J. S. O. Santos, S. Rault, Synthesis 2010 2804-2810.

[13] S. Perato, A. S. Voisin-Chiret, J. Sopková-de Oliveira Santos, R. Legay, H. Oulyadi, S. Rault, Tetrahedron 2012, 68, 1910-1917.

[14] A. S. Voisin-Chiret, M. Muraglia, G. Burzicki, S. Perato, F. Corbo, J. Sopková-de Oliveira Santos, C. Franchini, S. Rault, Tetrahedron 2010 66, 8000-8005.

[15] M. De Giorgi, A. S. Voisin-Chiret, J. Sopková-de Oliveira Santos, F. Corbo, C. Franchini, S. Rault, Tetrahedron 2011, 67, 6145-6154.

[16] S. Perato, M. De Giorgi, G. Burzicki, F. Legalite, S. Rault, A. S. VoisinChiret, Curr. Microw. Chem. 2014, 1, 75-80.

[17] A. S. Voisin-Chiret, G. Burzicki, S. Perato, M. De Giorgi, C. Franchini, J. Sopková-de Oliveira Santos, S. Rault, Tetrahedron 2012, 68, 4381-4389.

[18] S. Hedir, M. De Giorgi, J. Fogha, M. De Pascale, L.-B. Weiswald, E. Brotin, B. Marekha, C. Denoyelle, C. Denis, P. Suzanne, et al., Eur. J. Med. Chem. 2018, 159, 357-380.

[19] D. F. Veber, S. R. Johnson, H.-Y. Cheng, B. R. Smith, K. W. Ward, K. D Kopple, J. Med. Chem. 2002, 45, 2615-2623.

[20] R. Didziapetris, P. Japertas, A. Avdeef, A. Petrauskas, J. Drug Target. 2003, 11, 391-406.

[21] Z. Rankovic, J. Med. Chem. 2015, 58, 2584-2608.

[22] A. Avdeef, Absorption and Drug Development: Solubility, Permeability, and Charge State, John Wiley \& Sons, 2003.

[23] Y. Ran, S. H. Yalkowsky, J. Chem. Inf. Comput. Sci. 2001, 41, 354-357.

[24] T. J. Ritchie, S. J. F. Macdonald, R. J. Young, S. D. Pickett, Drug Discov. Today 2011, 16, 164-171.

[25] Y. Henchoz, D. Guillarme, S. Martel, S. Rudaz, J.-L. Veuthey, P.-A Carrupt, Anal. Bioanal. Chem. 2009, 394, 1919-1930.

[26] J. Lalut, B. B. Tournier, T. Cailly, C. Lecoutey, S. Corvaisier, A. Davis, C Ballandonne, M. Since, P. Millet, F. Fabis, et al., Eur. J. Med. Chem. 2016, 116, 90-101.

[27] V. N. Viswanadhan, A. K. Ghose, G. R. Revankar, R. K. Robins, J. Chem Inf. Comput. Sci. 1989, 29, 163-172.

[28] R. Mannhold, G. I. Poda, C. Ostermann, I. V. Tetko, J. Pharm. Sci. 2009 98, 861-893.

[29] M. Ishikawa, Y. Hashimoto, J. Med. Chem. 2011, 54, 1539-1554.

[30] X.-Q. Chen, O. S. Gudmundsson, M. J. Hageman, J. Med. Chem. 2012 55, 7945-7956.

[31] A.-C. Groo, M. De Pascale, A.-S. Voisin-Chiret, S. Corvaisier, M. Since, A. Malzert-Fréon, Eur. J. Pharm. Sci. Off. J. Eur. Fed. Pharm. Sci. 2017, 97, 218-226.

[32] M. Kansy, F. Senner, K. Gubernator, J. Med. Chem. 1998, 41, $1007-$ 1010.

[33] P. Wils, A. Warnery, V. Phung-Ba, S. Legrain, D. Scherman, J. Pharmacol. Exp. Ther. 1994, 269, 654-658.

[34] S. S. F. Leung, D. Sindhikara, M. P. Jacobson, J. Chem. Inf. Model. 2016 56, 924-929.

[35] M. Lúcio, J. L. F. C. Lima, S. Reis, Curr. Med. Chem. 2010, 17, 17951809

[36] F. Castelli, A. Raudino, M. Fresta, J. Colloid Interface Sci. 2005, 285, 110-117.

[37] M. Engelk, P. Bojarski, R. Bloss, H. Diehl, Biophys. Chem. 2001, 90 157-173.

[38] R. Pignatello, T. Musumeci, L. Basile, C. Carbone, G. Puglisi, J. Pharm Bioallied Sci. 2011, 3, 4-14.

[39] T. T. Mills, J. Huang, G. W. Feigenson, J. F. Nagle, Gen. Physiol. Biophys. 2009, 28, 126-139.

[40] W. Smeralda, M. Since, S. Corvaisier, R. Legay, A.-S. Voisin-Chiret, A Malzert-Freon, Eur. J. Pharm. Sci. 2019, 131, 75-83.

[41] J. D. Knight, A. D. Miranker, J. Mol. Biol. 2004, 341, 1175-1187.

[42] D. lacopetta, C. Rosano, F. Puoci, O. I. Parisi, C. Saturnino, A. Caruso, P. Longo, J. Ceramella, A. Malzert-Fréon, P. Dallemagne, et al., Eur. J. Pharm. Sci. 2017, 96, 263-272.

[43] N. S. Hatzakis, V. K. Bhatia, J. Larsen, K. L. Madsen, P.-Y. Bolinger, A H. Kunding, J. Castillo, U. Gether, P. Hedegård, D. Stamou, Nat. Chem. Biol. 2009, 5, 835-841. 
[44] S. S. Y. Chong, S. G. Taneva, J. M. C. Lee, R. B. Cornell, Biochemistry 2014, 53, 450-461.

[45] R. W. Gunasekara, Y. Zhao, Langmuir 2015, 31, 3919-3925.

[46] J. Ren, S. Lew, Z. Wang, E. London, Biochemistry 1997, 36, 1021310220.

[47] F. R. Maxfield, I. Tabas, Nature 2005, 438, 612-621.

[48] K. M. Taylor, M. A. Roseman, Biochemistry 1995, 34, 3841-3850.

[49] D. Illinger, G. Duportail, Y. Mely, N. Poirel-Morales, D. Gerard, J. G. Kuhry, Biochim. Biophys. Acta 1995, 1239, 58-66.

[50] H. Ferreira, M. Lúcio, B. de Castro, P. Gameiro, J. L. F. C. Lima, S. Reis, Anal. Bioanal. Chem. 2003, 377, 293-298.

[51] O. Stern, M. Volmer, 1919, 20, 183-188.

[52] M. Pinheiro, S. Pisco, A. S. Silva, C. Nunes, S. Reis, Int. J. Pharm. 2014, 466, 190-197.

[53] C. Nunes, D. Lopes, M. Pinheiro, C. Pereira-Leite, S. Reis, Pharm. Res. 2013, 30, 2097-2107.

[54] L. W. Thomas, C. Lam, S. W. Edwards, FEBS Lett. 2010, 584, 2981 2989.

[55] Discovery Studio Modeling Environment, Release 3.5, BIOVIA, San Diego, CA, 2012

[56] Schrödinger Release 2015-2, Schrödinger, LLC, New York, NY, 2017.

[57] B. Bard, S. Martel, P.-A. Carrupt, Eur. J. Pharm. Sci. Off. J. Eur. Fed. Pharm. Sci. 2008, 33, 230-240.

[58] F. Olson, C. A. Hunt, F. C. Szoka, W. J. Vail, D. Papahadjopoulos, Biochim. Biophys. Acta 1979, 557, 9-23.

[59] R. A. Demel, W. S. Geurts van Kessel, R. F. Zwaal, B. Roelofsen, L. L. van Deenen, Biochim. Biophys. Acta 1975, 406, 97-107.

[60] B. Berge, A. Renault, EPL Europhys. Lett. 1993, 21, 773

[61] M. Deleu, J.-M. Crowet, M. N. Nasir, L. Lins, Biochim. Biophys. Acta 2014 1838, 3171-3190.

[62] C. Bourlieu, G. Paboeuf, S. Chever, S. Pezennec, J.-F. Cavalier, F. Guyomarc'h, A. Deglaire, S. Bouhallab, D. Dupont, F. Carrière, et al., Colloids Surf. B Biointerfaces 2016, 143, 97-106. 
WILEY-VCH

FULL PAPER

\section{Table of Contents}

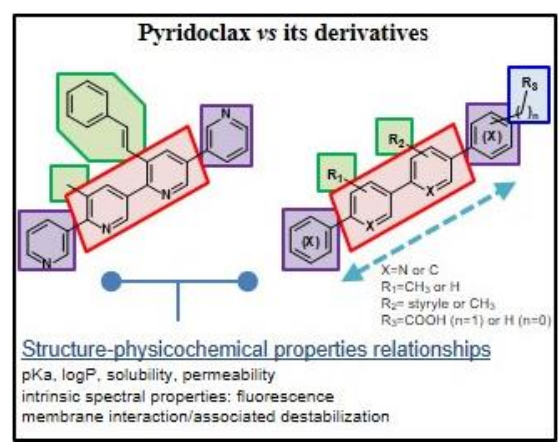

The experimental data assessed on Pyridoclax, a promising anticancer drug, and on its 18 sensibly selected structural analogs, have permitted to assess relative differences in terms of physico-chemical properties which could be determinant for their druggability, and hence for their drug development. 